\title{
Oncolytic Immunotherapy: Conceptual Evolution, Current Strategies, and Future Perspectives
}

\author{
Zong Sheng Guo 1,2*, Zuqiang Liu 1,2, Stacy Kowalsky ${ }^{1,2}$, Mathilde Feist ${ }^{1,2,3}$, \\ Pawel Kalinski ${ }^{1,2,4}$, Binfeng Lu $^{1,4}$, Walter J. Storkus ${ }^{1,4,5}$ and David L. Bartlett ${ }^{1,2}$ \\ ${ }^{1}$ University of Pittsburgh Cancer Institute, Pittsburgh, PA, USA, ${ }^{2}$ Department of Surgery, University of Pittsburgh School of \\ Medicine, Pittsburgh, PA, USA, ${ }^{3}$ Department of Surgery, CCM/CVK, Charité - Universitaetsmedizin Berlin, Berlin, Germany, \\ ${ }^{4}$ Department of Immunology, University of Pittsburgh School of Medicine, Pittsburgh, PA, USA, ${ }^{5}$ Department of Dermatology, \\ University of Pittsburgh School of Medicine, Pittsburgh, PA, USA
}

\section{OPEN ACCESS}

Edited by:

Benjamin Gesundheit,

Cell-El Ltd., Israel

Reviewed by:

Luis de la Cruz-Merino, Hospital Universitario Virgen

Macarena, Spain

Graham Robert Leggatt, The University of Queensland, Australia

*Correspondence: Zong Sheng Guo guozs@upmc.edu

Specialty section: This article was submitted to

Cancer Immunity and Immunotherapy, a section of the journal Frontiers in Immunology

Received: 27 February 2017 Accepted: 25 April 2017

Published: 15 May 2017

Citation:

Guo ZS, Liu Z, Kowalsky S, Feist M, Kalinski P, Lu B, Storkus WJ and Bartlett DL (2017) Oncolytic Immunotherapy: Conceptual Evolution, Current Strategies, and Future Perspectives.

Front. Immunol. 8:555. doi: 10.3389/fimmu.2017.00555
The concept of oncolytic virus (OV)-mediated cancer therapy has been shifted from an operational virotherapy paradigm to an immunotherapy. OVs often induce immunogenic cell death (ICD) of cancer cells, and they may interact directly with immune cells as well to prime antitumor immunity. We and others have developed a number of strategies to further stimulate antitumor immunity and to productively modulate the tumor microenvironment (TME) for potent and sustained antitumor immune cell activity. First, OVs have been engineered or combined with other ICD inducers to promote more effective $T$ cell cross-priming, and in many cases, the breaking of functional immune tolerance. Second, OVs may be armed to express Th1-stimulatory cytokines/chemokines or costimulators to recruit and sustain the potent antitumor immunity into the TME to focus their therapeutic activity within the sites of disease. Third, combinations of OV with immunomodulatory drugs or antibodies that recondition the TME have proven to be highly promising in early studies. Fourth, combinations of OVs with other immunotherapeutic regimens (such as prime-boost cancer vaccines, CAR T cells; armed with bispecific T-cell engagers) have also yielded promising preliminary findings. Finally, OVs have been combined with immune checkpoint blockade, with robust antitumor efficacy being observed in pilot evaluations. Despite some expected hurdles for the rapid translation of OV-based stateof-the-art protocols, we believe that a cohort of these novel approaches will join the repertoire of standard cancer treatment options in the near future.

\footnotetext{
Keywords: immunogenic cell death, ICD inducer, antigen, cross-presentation, immune checkpoint blockade, antitumor immunity, $\mathrm{T}$ cells, combination
}

\section{INTRODUCTION}

Successful cancer therapy using oncolytic viruses $(\mathrm{OV})$ is predicated on at least three major (and coordinate) mechanisms of action. Among them, the first is the direct infection of cancer cells and endothelial cells and the subsequent oncolysis of these cells in the tumor microenvironment (TME). The second involves indirect effects of necrosis/apoptosis of uninfected cancer cells and associated endothelial cells in the tumor-associated vasculature leading to reduced angiogenesis (1-3). Finally, antitumor (and antiviral) immunity is elicited/expanded by the OV as a consequence of improved antigen cross-priming and recruitment of immune cells into the TME. More 
than 10 years ago, most, if not all, investigators thought that the direct oncolysis was the only major mechanism by which OVs inhibited tumor growth, leading to the terminology of "oncolytic virotherapy," coined by Kirn in 2001 (4). Later, investigators discovered that the host immune response was critical to the antitumor efficacy of oncolytic virotherapy. Briefly, this has been shown through multiple approaches including the use of (1) an OV encoding a tumor antigen to potently activate therapeutic T cell responses (5); (2) reovirus infection of tumor cells to prime antitumor immunity capable of reducing metastatic disease burden (6); and (3) $\mathrm{CD}^{+} \mathrm{T}$ cell depletion resulting in the loss of efficacy associated with OV-based treatment (7). Thus, OV represents a novel form of immunotherapy (8), with Rommelaere and associates formally advocating the term "oncolytic immunotherapy" in their article published in 2011 (9). Since then many other investigators, including our group, have adopted this terminology (10-14). As most investigators have discovered, single modality therapies (including OV) may be insufficient to effect cure in the cancer setting, mandating the development of combination protocols implementing antitumor agents capable of yielding additive or synergistic antitumor benefits. Our discussion will focus on combination regimens likely to yield superior antitumor immunity associated with improved treatment outcomes.

\section{THE CONCEPTUAL SHIFT FROM VIROTHERAPY TO ONCOLYTIC IMMUNOTHERAPY}

Although the use of viruses as oncolytic agents has a rich history, the application of genetically engineered viruses to selectively target cancer cells is a relatively recent adaptation (15). The first research article reporting the use of a genetically engineered OV was published by Martuza and colleagues in 1991 (16), in which the authors showed that infection with a thymidine kinase $(t k)$ gene-deleted herpes simplex virus (HSV) led to the death of multiple human glioma cell lines, as well as, primary cultures of human glioma cells. Furthermore, they demonstrated that intratumoral inoculation of the $t k$ gene-deleted HSV led to the slowed growth of human glioma xenografts in SCID mice and to the extended overall survival of these animals. In most early studies, it was thought that the major mechanism associated with OV treatment benefit involved selective viral replication in cancer cells and consequent tumor cell lysis or apoptosis (17). For example, an oncolytic HSV-mediated tumor inhibition showed equivalent effects in immune-competent and immuneincompetent mice, suggesting that viral oncolysis and not the host immune response was the primary mechanism linked to tumor destruction (18). Thus, investigators at that time paid significant attention to remove viral genes that would limit tumor cell lysis or apoptosis, such as the adenovirus gene encoding E1B-19 kDa protein (19) or vaccinia virus (VACV) genes for SPI-1 and SPI-2 (20). In addition, to accentuate such pathways, OVs commonly incorporated suicide genes or genes promoting apoptosis such as a suicide gene encoding purine nucleotide phosphorylase (21), apoptosis-inducing gene TRAIL (22), or tumor suppressor gene TP53 $(23,24)$.
Yet, investigators repeatedly noticed the critical role of antitumor T cells in OV-mediated therapeutic efficacy in their studies. In 1999, Martuza and associates found that infection of established CT26 tumors in mice using an HSV-1 OV G207 led to the generation of highly specific, systemic antitumor immunity (25). Later, Vile and associates demonstrated that tumor infection by oncolytic reovirus primes adaptive antitumor immunity (6). They also showed that $\mathrm{CD}^{+} \mathrm{T}$ cells played a critical role in the therapeutic efficacy of intratumorally delivered vesicular stomatitis virus (VSV), with these T cells specific for immunodominant epitopes derived from both viral- and tumor-associated target proteins (5). The authors utilized two approaches to show the important roles of $\mathrm{CD}^{+} \mathrm{T}$ cells in this therapy. First, by increasing the circulating levels of tumor antigen-specific $\mathrm{T}$ cells using adoptive $\mathrm{T}$ cell transfer, in combination with intratumoral virotherapy, the investigators observed significantly enhanced therapeutic efficacy over either monotherapy. Second, the integration of a tumor-associated antigen (TAA) within the oncolytic VSV was found to increase the level of activation of naive $T$ cells recognizing that antigen, in association with enhanced antitumor activity. As a consequence, they termed their approach an "oncolytic immunovirotherapy" (5). Zhang and associates showed that tumor destruction after delivery of an HSV2-based $\mathrm{OV}$ (FusOn-H2) in vivo induced potent antitumor immune responses in a syngeneic neuroblastoma model $(26,27)$. Even UV-inactivated Sendai virus (particle) was shown to eradicate tumors by promoting antitumor immunity as a consequence of blocking the immunosuppressive action of regulatory $\mathrm{T}$ cells (Tregs), believed to be mediated via the viral particle-induced secretion of IL-6 from activated dendritic cell (DC), independent of cancer cell infection (28). In addition, investigators have developed OV armed with genes to stimulate immune responses, as showcased by T-VEC, originally constructed and tested in 2003 (29). On the basis of an increasing body of evidence, we and others concluded that OVs are promising novel immunotherapeutic strategies $(8,30)$. More recently, Bhat et al. have coined the term "oncolytic immunotherapy" in reference of their study of oncolytic parvovirus to activate NK cells capable of killing cancer cells in 2011 (9). Hemminki and associates have also applied this term in their clinical study using an oncolytic AdV expressing CD40L, where they observed induction of potent tumor antigen (surviving)-specific $\mathrm{CD} 8^{+} \mathrm{T}$ cells associated with robust antitumor activity (10). Many in the field have now adopted this nomenclature as it is believed to best reflect the intrinsic immunologic mechanisms of action associated with this class of novel antitumor agents $(8,10-14,30,31)$.

\section{CURRENT STRATEGIES IN ONCOLYTIC IMMUNOTHERAPY}

In this section, we will introduce the concept of tumor immunogenic cell death (ICD), how OVs induce ICD, and how this may lead to the development of potent, durable antitumor immune responses in treated individuals. We will then discuss current concepts for preclinical studies and the clinical implementation of OVs as monotherapies or combination protocols integrating a range of chemotherapeutic agents or immunomodulatory compounds. 


\section{Immunogenic Cell Death (ICD)}

In a previous review, we summarized the developmental concept of ICD and key features of this type of cell death that leads to robust antitumor immune responses (12). Here, we will update this important and evolving paradigm and discuss new findings related to the role of OV-associated ICD with the development of therapeutic antitumor immunity.

Intrinsic to this discussion is the question of how the immune system senses danger associated with pathogenic infection or the development of a pathologic state (such as cancer). As Janeway summarized, the immune system distinguishes self from non-self "events" based on the surveillance of differences and danger signals predicated on so-called immune signals 1, 2, 3, and 0 (32). Signal 0 derives from pathogens and is now called pathogen-associated molecular patterns (PAMPs). In 1994, Matzinger proposed that danger signals are also communicated from the inside of dying cells, i.e., damage-associated molecular patterns (DAMPs) $(33,34)$. In recent years, ICD in tumor cells has been viewed as critical to the development and sustainability of protective adaptive immune responses. To qualify as ICD, dying tumor cells must possess characteristics associated with immune signal 0 (danger) and signal 3 (inflammatory cytokines) that are required to instruct host DCs to take up tumor cell bodies, to mature and process these antigens into MHC-presented peptides, and to cross-prime antitumor $\mathrm{T}$ cells in a manner that results in the activation and expansion of cytotoxic $\mathrm{T}$ cells capable of emigration back to sites of disease.

In 2014, a group of key investigators from around the world working on ICD reached a consensus that there were at least three key feature molecules (DAMPs) required for the process of ICD. These include cell surface-exposed calreticulin, extracellular ATP and high mobility group box 1 (HMGB1), and/or the pathways allowing for their emission from dying cells, such as endoplasmic reticulum stress, autophagy, and necrotic plasma membrane permeabilization (35). When Zitvogel, Kroemer, and others originally proposed the concept, ICD included only the consideration of immunogenic apoptosis $(36,37)$. However, in 2013, our group, and that of Inoue and Tani, independently proposed that ICD includes not only immunogenic apoptosis but also necroptosis, autophagic cell death, and pyroptosis of cancer cells $(30,38)$. This extension has been validated by a number of recent studies. For example, necroptotic cancer cells induce ICD, and vaccination with such dying cancer cells induces efficient antitumor immunity (39). With a greater understanding of various mechanisms of cell death, the concept of ICD has continued to evolve. This year, Galluzzi and colleagues have further revised the ICD concept to now include additional types of cell death (such as necroptosis, pyroptosis) as we and other groups had originally proposed in $2013(30,38,40)$.

A variety of therapeutic regimens and factors induce ICD in cancer cells (41). They include physical (radiotherapy and photodynamic therapy) (42), chemical (such as anthracyclines, oxaliplatin) (41), and biological ones. These biological agents include some OVs, immunogenic peptide (43), and other microorganisms and their products as they are potent PAMPs and more. We may arbitrarily think that infection with OVs automatically makes tumor cells highly immunogenic; however, this is not a guarantee as many viruses have evolved molecular mechanisms that subvert the exposure of DAMPs (such as ecto-CRT), thereby limiting the magnitude of ICD and thus consequent immune detection of such infected cells $(12,44)$. Indeed, such viruses induce cell death via non-immunogenic (sterile) apoptosis.

\section{OVs Induce Bona Fide ICD in Cancer Cells and May Interact Directly with Immune Cells, Leading to the Activation of Innate and Adaptive Immune Cells}

Even though a variety of OVs have been shown to induce some features of ICD, few have been conclusively shown to represent bona fide inducers of tumor ICD. Based on the consensusrecognized ICD signature molecules (i.e., ecto-CRT, extracellular ATP, and HMGB1), only one OV thus far appears to meet the criteria for designation as an ICD-promoter: coxsackievirus B3 (45). However, a number of other OVs may also induce bona fide ICD, as they indeed serve to prime/induce adaptive antitumor immunity in vivo. The list is quite long and includes oncolytic adenovirus (46), influenza virus (47), $\operatorname{HSV}(25,48,49)$, measles virus (MeV) (50), NDV (51), VSV (5), and Sendai virus (52). However, we wish to emphasize that significantly more investigations will be required to validate such conjecture.

Some unarmed OVs possess the potential to activate innate and adaptive immunity. For example, an HSV-2 mutant, called $\triangle \mathrm{PK}$ (due to the deletion of ICP10 that has protein kinase activity), has strong oncolytic activity for melanoma, induced mainly by a mechanism other than replication-induced cell lysis. It was found that it induced multiple non-redundant programmed cell death pathways (53). $\Delta \mathrm{PK}$ inhibited the secretion of IL-10 from melanoma cells through virus replication and $c$-Jun $N$-terminal kinase/c-Jun activation. The virus-induced IL-10 inhibition led to enhanced cell surface expression of MHC class I chain-related protein $\mathrm{A}$, the ligand for NKG2D receptor expressed on NK and $\mathrm{CD}^{+} \mathrm{T}$-cells. Concomitantly, $\Delta \mathrm{PK}$ also enhanced the secretion of TNF- $\alpha$, GM-CSF, and IL- $1 \beta$ through autophagy-mediated activation pathways of Toll-like receptor 2 and pyroptosis and inhibited the expression of CTLA-4, one of the key negative immune checkpoint molecules (54).

Interestingly, ICD is not the only pathway by which OVs may modulate the host antitumor immune response. OVs may interact directly with immune cells to prime antitumor as well as antiviral immune responses. Reovirus may function as a PAMP interacting directly with DC, thus promoting DC maturation and stimulating the production of pro-inflammatory cytokines that may activate innate antitumor immunity (55). In contrast, reovirus may also infect tumor cells, leading to the (cross) priming of adaptive antitumor immunity (6). VSV can infect DC, leading to the improved capacity of these antigen-presenting cells to prime innate and adaptive antitumor immunity (56). The interaction of VACV with DC is a complex story. In vivo, both $\mathrm{CD}^{+}$and $\mathrm{CD}^{-} \mathrm{DC}$ are infected with VACV, resulting in the generalized upregulation in the expression of costimulatory molecules. However, IL-12 production is restricted to a subset of non-infected DCs (57). Interestingly, VACV may modulate the biological activity of another important immune cell type in the TME. Tumor-associated 


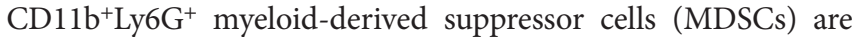
normally immunosuppressive. Oncolytic VACV recruits MDSC with enhanced iNOS expression, which leads to beneficial antitumor activity. Depletion of iNOS-producing cells leads to very rapid tumor growth postvirus injection. These results suggest that the virus-induced iNOS ${ }^{+}$MDSCs could represent an important antitumor effector cell population in the TME (58).

Many studies have shown that OVs elicited antitumor immunity, and this significantly contributed to the overall efficacy of the virus-mediated cancer therapy. As early as 1999, Toda et al. have shown that an oncolytic HSV (G207) could function as an in situ vaccine to induce specific antitumor immunity (25). An $\mathrm{OV}$ (e.g., MeV, Parvovirus $\mathrm{H}-1$, or reovirus) would induce cancer cell oncolysis and allows DC to cross-prime tumor-specific CD8 ${ }^{+}$ $\mathrm{T}$ cell response $(6,59,60)$. As we will discuss later, arming the OVs with immune-stimulatory molecules would further promote eliciting potent antitumor immunity. A number of groups have shown that when the OVs encode a TAA, these OVs worked effectively as cancer vaccines (61-64). The antitumor immunity mounted by OVs have also been demonstrated in human cancer patients treated with oncolytic $\mathrm{MeV}(62,65), \mathrm{HSV}$ (66), AdV (67), and VACV(68).

\section{OVs Expressing Th1-Stimulatory Molecules}

To enhance the efficacy of antitumor immunity (Figure 1), many investigators have armed OVs with immune stimulatory genes. These may include costimulatory molecules, cytokines, and chemokines, such as IL-2, IL-12, IL-18, IFN- $\alpha / \beta$, TNF- $\alpha$, or GM-CSF, that are capable of promoting the development of cytotoxic immune effector cells.

All of these viruses are designed to further stimulate systemic antitumor immunity and to promote the trafficking of immune cells into the TME. Arguably, the best-studied OVs have been those armed with GM-CSF. The first such agent in the class approved by FDA is T-VEC, a HSV armed with GM-CSF for the treatment of patients with advanced-stage melanoma. PexaVec, a VACV armed with GM-CSF, is currently being evaluated in a PHOCUS (phase III) global clinical trial in the setting of advanced-stage hepatocellular carcinoma (HCC). An additional oncolytic AdV armed with GM-CSF, designated CG0070, is being assessed for efficacy in a phase III clinical trial for the treatment of high-grade non-muscle invasive bladder cancer after failure to treatment with Bacillus Calmette-Guérin (BCG).

$\mathrm{T}-\mathrm{VEC}$ represents a rationally designed OV to stimulate antitumor immunity based on engineering the viral vector to encode an immune-stimulatory gene. First, the virus was modified through deletion of two non-essential viral genes for replication in cancer cells (ICP34.5 and ICP47). ICP34.5 is a neurovirulence factor gene and its deletion attenuates viral pathogenicity and enhances tumor-selective replication (69). The second viral gene is ICP47, and its encoded protein enhances viral neurovirulence by limiting $\mathrm{CD}^{+} \mathrm{T}$ cell responses (70). Deletion of the ICP47 gene reduces viral-mediated suppression of antigen presentation and increases the expression of the HSV Us ${ }^{11}$ gene. The virus

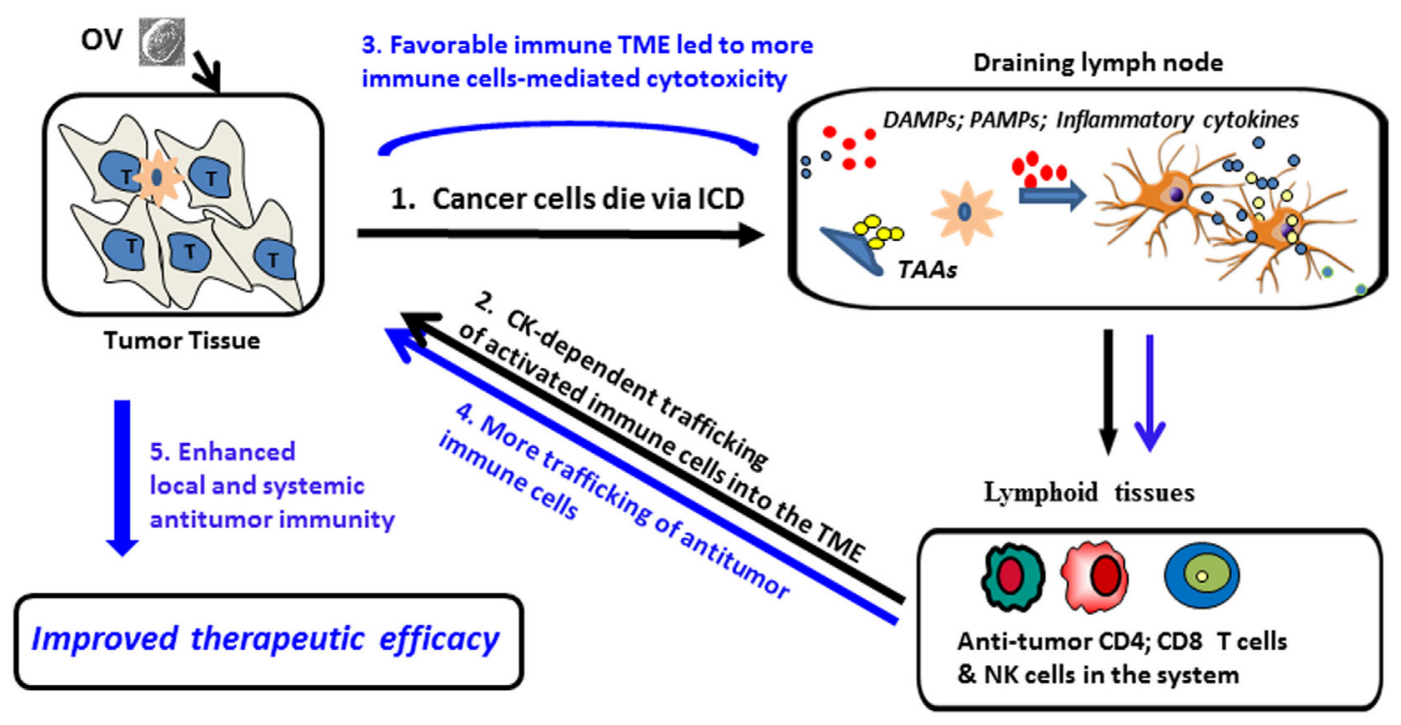

FIGURE 1 | Proposed model for ICD and pro-inflammatory cytokines/chemokines (Th1) promotion of oncolytic virus (OV)-mediated antitumorimmunity. (1) OV infects tumor cells and induces ICD, leading to the release/presentation of signal 0 [damage-associated molecular patterns (DAMPs) and pathogen-associated molecular patterns (PAMPs)], along with tumor-associated antigens (TAAs) to dendritic cells (DCs), resulting in DC activation and Ag cross-presentation to antiviral and antitumor immune cells (activated NK cells, CD4+ and CD8 ${ }^{+} \mathrm{T}$ cells), followed by clonal expansion and maturation of antitumor T effector cells. (2) Cytokines/chemokines released during the acute inflammation in the tumor microenvironment (TME) promote trafficking of therapy-induced immune cells into the TME; (3) inflammation in the TME is sponsored by both viral- and tumor-reactive T cells, with immune-mediated eradication of tumor cells and tumor-associated stromal cells. Additional danger signals (signal 0), inflammatory cytokines, and chemokines (signal 3) and TAAs (signal 1) further activate tumor-associated DCs, overcoming local immunosuppression and prolonging the survival and functionality of antitumor immune cell populations; (4) reiterative rounds of DC-mediated cross-priming continue to allow for delivery of new (reinforcement) T immune effector cells into the TME (5) allowing for sustained antitumor efficacy within disseminated sites of disease. 
was then modified by insertion of cDNA encoding the cytokine GM-CSF. The infection of cancer cells by T-VEC induces ICD and local expression of GM-CSF, resulting in the recruitment, activation, and maturation of antigen-presenting cells, which are competent to promote tumor-specific T-cell responses (29).

Other OVs have been armed with chemokine genes. Expression of CCL5 (RANTES) from an OV has been shown to recruit DC, macrophages, $\mathrm{NK}$, and $\mathrm{CD}^{+} \mathrm{T}$ cells into tumor sites, in association with the development of enhanced tumor antigen-specific $\mathrm{CD}^{+} \mathrm{T}$ cell and NK cell-mediated immune responses $(71,72)$. Recently, we have developed an OV encoding the chemokine CXCL11, designed to recruit $\mathrm{CXCR}^{+}$antitumor $\mathrm{T}$ effector cells and NK cells into the TME to mediate improve therapeutic efficacy (73). Although infection with this OV indeed led to these expected outcomes, we unexpectedly observed that vvDDCXCL11 (but not parental vvDD) induced a systemic increase in tumor-specific IFN- $\gamma$-producing $\mathrm{CD}^{+} \mathrm{T}$ cells in treated animals. In an immunogenic tumor model, this therapy led to tumor regression and extended survival benefit, which was strictly dependent on $\mathrm{CD}^{+} \mathrm{T}$ cells and IFN- $\gamma$, but not $\mathrm{CD} 4^{+} \mathrm{T}$ cells (73). However, in a non-immunogenic tumor model, treatment with vvDD-CXCL11 monotherapy was not effective, necessitating its combination with a drug cocktail chosen for its ability to (re) condition the TME, which led to improved therapeutic efficacy in the MC38 colon tumor model (74).

Oncolytic virus expressing costimulatory molecules have also been explored. An oncolytic VACV expressing the 4-1BBL T-cell costimulatory molecule ( $\mathrm{rV}-4-1 \mathrm{BBL}$ ) was shown to be moderately effective in treating poorly immunogenic B16 melanomas in mice. Interestingly, when $\mathrm{rV}-4-1 \mathrm{BBL}$ treatment was combined with a lymphodepletion regimen, the authors observed enhanced tumor MHC class I expression, the promotion of viral persistence, and the rescue of effector-memory $\mathrm{CD}^{+} \mathrm{T}$ cells in association with improved therapeutic efficacy (75). When an oncolytic VACV was combined with an agonist antibody $(\mathrm{Ab})$ specific for the costimulatory molecule 4-1BB (CD137), the dual treatment led to enhanced antitumor immunity and robust suppression of tumor growth in murine models (76). Enhanced immunity was associated with increased numbers of $\left(\mathrm{CD} 11 \mathrm{~b}^{+}\right.$and $\left.\mathrm{CD} 11 \mathrm{c}^{+}\right)$myeloid cells in tumor draining lymph nodes and enhanced infiltration of both NK cells and CD8 ${ }^{+} \mathrm{T}$ effector cells into the TME (76). Allison and associates have recently constructed an oncolytic NDV expressing the inducible costimulator and shown that when applied as an intratumoral therapy in combination with systemic CTLA-4 blockade, which treated mice exhibit enhanced infiltration of activated $\mathrm{T}$ cells in both virus-injected and uninjected, distal tumors that is curative in the B16-F10 tumor model (77).

We and other investigators in the field continue to search for new and exciting factors for inclusion in cutting-edge OV-based immunotherapies. In this regard, one of our groups has recently discovered the potent antitumor action of the IL-1 family member IL-36 $\gamma$, which coordinately activates $\mathrm{CD}^{+} \mathrm{T}$ cells, NK cells, and $\mathrm{T} \gamma / \delta$ cells and synergizes with TCR activation and the type- 1 polarizing cytokine IL-12 (78). When present within the TME, IL-36y exerts profound antitumor activity in vivo, suggesting the great potential of this pro-inflammatory cytokine in OV-based cancer therapeutics.

\section{Combination of OV with Other Therapeutic Regimens/Drugs to Favorably Correct and Optimize the Immunologic TME}

The cellular cross-talk between tumor cells and stromal cells within the TME, which is often mediated through soluble factors, creates an immunosuppressive environment that allows for enhanced viral replication and oncolytic activity in immune-deficient mice (79). The expression of VEGFR, which promotes tumor angiogenesis and progression, sensitizes the tumor vasculature to infection by oncolytic VACV (80). However, the TME coordinately inhibits protective antitumor immune responses that are crucial to the overall therapeutic efficacy of OVs applied to the immunocompetent (tumor-bearing) host. As a consequence, investigators have developed a variety of strategies including arming viruses with therapeutic genes or coapplying pharmaceutical interventions that promote ICD and/or that facilitate antigen cross-presentation in support of developing therapeutic antitumor $\mathrm{T}$ cell responses (81). We will discuss six strategies in this section.

\section{Combination of OV with Conventional Chemotherapeutic Agents That Induce ICD}

Many traditional chemotherapeutic agents possess the capacity to enhance host immunity (82). It is therefore logical to combine OV with this type of conventional drug to effect greater clinical benefit in the cancer setting. Combination treatments utilizing OVs and other pharmaceutical drugs have been reviewed extensively by Forbes et al. (83). We will discuss two recent studies to illustrate the most critical points. In the first study, the authors used autophagy stimulating or inhibitory drugs to determine if autophagy meaningfully impacts the outcome of oncolytic virotherapy. They showed that chloroquine or rapamycin significantly potentiate NDV-mediated oncolytic activity in mice bearing drug-resistant lung cancer (84). In this case, the exact mechanisms underlying treatment benefit remain to be elucidated. In another study, treatment with HSV-1 ICP0 null OV KM100 alone was determined insufficient to break immune tolerance in a breast tumor model; however, Workenhe et al. showed that by combining the virus with the ICD-inducing chemotherapy agent mitoxantrone, a significant survival benefit was gained for mice bearing Her2/neu TUBO-derived tumors. The take-home lesson was that such combination OV-based regimens coordinately enhances tumor immunogenicity, breaks immunologic tolerance established toward TAAs, and elicits superior therapeutic benefit (85).

\section{Combination with Other Immunotherapies to Recruit and Sustain Protective Antitumor Immunity in the TME}

By using tumor explant models, we investigated the impact of 3 in-clinic drugs for their ability to productively modulate the inflammatory characteristics of the TME: IFN- $\alpha$, poly-I:C (a TLR3 ligand), and a COX-2 inhibitor (86-88). Tumor tissues reacted to individual drugs heterogeneously. A combination of IFN- $\alpha$ and poly-I:C uniformly enhanced the production of preferred (type-1 T cell recruiting) chemokines CXCL10 and CCL5, while reducing local production of CCL22, known to recruit 
suppressor cell populations. The addition of a COX inhibitor to this combination further enhanced these effects (86). We then applied this cocktail of agents to a colon tumor model in conjunction with the delivery of an oncolytic VACV. Sequential treatment with the virus vvCXCL11 and then the drug cocktail resulted in the upregulated expression of Th1-attracting CKs and a reduction in expression of the Treg-attracting CKs (CCL22 and CXCL12), in concert with enhanced trafficking of tumorspecific CD8 ${ }^{+} \mathrm{T}$ cells and NK cells into the TME. Notably, this combination regimen led to the greatest degree of therapeutic antitumor activity and to the long-term survival of the treated mice (74).

Another strategy is to engineer OV with a gene that serves as an antagonist to a dominant suppressor cell type or suppressor soluble mediator in the TME. MDSCs are one of the major regulatory cell subpopulations in the TME, where they promote tumor growth and progression (89). The inhibition of tumorderived prostaglandin- $\mathrm{E}_{2}\left(\mathrm{PGE}_{2}\right)$ would be expected to block the induction of MDSCs and the recovery of NK cell activity (90). 15-Prostaglandin dehydrogenase (15-PGDH) is a tumor suppressor protein that is responsible for the degradation of $\mathrm{PGE}_{2}$. Walker et al. have constructed an oncolytic HSV expressing 15-PGDH and demonstrated that the delivery of this virus mitigates immune suppression and inhibits the growth of primary and metastatic breast cancer in a murine model (91). Recently, Hou et al. have also shown that an oncolytic VACV expressing this enzyme overcomes local immunosuppression, leading to profound changes in protective immune function within the TME. Such engineered OVs promote robust adaptive antitumor immunity and sensitize established and previously resistant tumors to regulation by immunotherapies (92).

\section{Use a Vaccine Monotherapies or Combination Therapies}

That OVs may function as effective cancer vaccines and impediments to their biologic activity have been discussed extensively in several recent reviews $(30,93-95)$. Here, we will focus on a discussion of prime-boost strategies as these relate to the use of OVs as cancer vaccines.

Heterologous prime-boost vaccination, a well-documented regimen to elicit robust $\mathrm{CD}^{+} \mathrm{T}$ cell responses, has been applied within the context of oncolytic immunotherapy. The first such study was carried out by Wan and colleagues, employing an antigen-expressing VSV and AdV. Intranasal delivery of the OV VSV-hDCT resulted in the activation of both $\mathrm{CD}^{+}$and $\mathrm{CD}^{+}$DCT-specific T-cells. These responses were significantly increased by subsequent booster vaccination using recombinant Ad (Ad)-hDCT. This regimen resulted in enhanced therapeutic efficacy against established B16-F10 melanomas in mice (96). In another study, the authors used recombinant VSV as a booster vaccine and demonstrated a massive increase in the secondary expansion of $\mathrm{CD}^{+}$antigen-specific $\mathrm{T}$ cells after priming with recombinant AdV (97). Vile et al. have also recently showed that a prime-boost vaccine regimen using distinct OVs (reovirus and VSV), when applied in combination with immune checkpoint blockade results in improved antitumor immunity/ efficacy in the B16 melanoma model (98). Song, Kim, and others have developed a hybrid regimen using a complex of DNA and oncolytic AdV to treat malignant melanoma in a syngeneic mouse model (99). In this protocol, MART1 plasmid was used as a DNA-based vaccine to induce specific immunity, while the gene encoding murine GM-CSF and shRNA against mouse TGF- $\beta 2$ were codelivered with MART- 1 cDNA via an oncolytic AdV. This heterologous prime-boost vaccine strategy resulted in delayed tumor growth, likely resulting from (i) the induction of anti-MART1 T effector cells, (ii) enhanced antigen-presentation driven by GM-CSF and TGF- $\beta 2$ shRNA, (iii) tumor growth inhibition by TGF- $\beta 2$ shRNA, and (iv) tumor cell-specific OVinduced oncolysis (99).

\section{Combination with CAR T Cell-Based Adoptive Immunotherapy}

CAR T cells represent one of the most promising new approaches in cancer immunotherapy (100), with only a single study thus far integrating OV (101). In this report, an oncolytic Ad (Ad5 $\Delta 24)$ was armed with chemokine genes CCL5 and IL-15 and applied as a recruiter (via CCL5) and sustainer (via IL-15) of CAR$\mathrm{T}$ cells (reactive against the tumor-associated ganglioside GD2) into/within the TME. Application of the OV was observed to enhance the function of CAR T cells in vivo, with the combination immunotherapy extending overall survival in mice bearing neuroblastomas.

\section{Combination with Bispecific T-Cell Engagers (BiTEs)}

So far two studies have explored this novel approach. Song and associates constructed an oncolytic VACV encoding a secretory BiTE composed of two single-chain variable fragments specific for CD3 and the tumor cell surface antigen EphA2 (EphA2TEA-VV) (102). This virus, when combined with human T cells, exhibited potent antitumor activity in a lung cancer xenograft model. Earlier this year, Alemany and associates generated an oncolytic AdV encoding a BiTE (cBiTE) coordinately targeting EGFR and CD3 (ICOVIR-15K-cBiTE). Intratumoral injection of this recombinant $\mathrm{AdV}$ increased the persistence and accumulation of tumor-infiltrating T cells in vivo. This OV, when combined with peripheral blood mononuclear cells or $\mathrm{T}$ cells exhibited enhanced antitumor efficacy (103). The results from these two studies suggest that BiTE-armed OVs may overcome some key limitations associated with current oncolytic virotherapy-based strategies.

\section{Combination with Complement Inhibition}

Natural barriers in the blood, including neutralizing antibodies and complement, likely limit our ability to repeatedly administer the same OVs intravenously. As a consequence, it makes sense to consider means by which to coordinately inhibit complement activation to improve the utility and antitumor efficacy of OV-based immunotherapies. We showed that inhibitors of C5 complement enhanced the infection of cancer cells by VACV in vitro, even in the absence of antivaccinia antibodies (104). In a recent study, Evgin et al. demonstrated that in immunized rats, complement depletion stabilized VACV in the blood, resulting in the improved delivery of virus into the TME (105). 


\section{Combination with Immune Checkpoint Blockade}

Immune checkpoint blockade-based immunotherapy has made major advances over the past several years, to now become standard of care in the setting of many forms of cancer. Since the anti-CTLA4 Ab (ipilimumab) was FDA approved for use in patients with advanced-stage melanoma in 2011, immune checkpoint antagonists (including anti-CTLA4 and anti-PD-1/PD-L1 antibodies) have now been approved for use against six forms of cancer. Immune checkpoint molecules are a natural means used by the immune system to maintain homeostasis, ensuring self-tolerance and the prevention of pathologic autoimmunity. In tumor tissues, however, these signals are often upregulated, allowing for progressively growing tumors to evade local protective immune responses (106).

Despite enthusiasm for the continued clinical use of immune checkpoint blockade as a general strategy to combat cancer, this approach works best in patients who exhibit existing evidence of ongoing antitumor immune responses, and it fails in cases where the TME is devoid of a protective immune signature. Furthermore, even in the setting of advanced-stage melanoma, only $15-25 \%$ patients exhibit durable objective clinical responses. Thus, there exists obvious potential for synergy between therapeutic regimens using OVs and immune checkpoint blockade. Mechanistically, OVs offer the possibility of priming, boosting, and recruiting effector $\mathrm{T}$ cells into the TME, where immune checkpoint blockade may serve to enhance/sustain the potency of antitumor TIL via the removal of inhibitory signals $(94,107)$.

In such combination immunotherapies, the immune checkpoint antagonist $\mathrm{Ab}$ could be physically delivered as a protein or encoded by a recombinant OV used to infected cancer cells. The first study for such a combination approach was published by Hemminki and his team in 2012, demonstrating that targeted cancer immunotherapy could be achieved using an oncolytic $\mathrm{AdV}$ encoding a fully humanized monoclonal $\mathrm{Ab}$ reactive against CTLA-4 (108). Since then, several original research papers on this exciting combination strategy have been published (109-118).

Zamarin and others demonstrated in mouse models that localized immunotherapy with oncolytic NDV combined with anti-CTLA4 $\mathrm{Ab}$ could cure the majority of treated tumorbearing mice, while treatment with NDV alone was effective in only $10 \%$ of cases. Importantly, this combinatorial strategy was observed to induce an immune response against both virally infected and control, uninfected tumors, with minimal reactivity noted against unrelated, third-party tumors. Interestingly, the antitumor efficacy of this approach was dependent on CD8 ${ }^{+}$ T-cells, NK cells, and type I IFN, but not on oncolysis. Treatment with this combination of oncolytic NDV and anti-CTLA4 Ab led to systemic tumor rejection and subsequent protection of the host against tumor rechallenge in poorly immunogenic tumor models (111).

Vile and colleagues have used a prime-boost vaccine regimen with separate OVs in concert with immune checkpoint blockade to further improve antitumor efficacy in combination approaches (98). They hypothesized that reovirus-induced $\mathrm{CD}^{+}$antitumor $\mathrm{T}$ cell responses, when combined with the VSV-ASMEL-induced $\mathrm{CD}^{+}$Th17 responses, would result in potent antitumor immunity/efficacy. In their study, tumor-bearing mice were first treated with intratumoral injection of reovirus, followed by intravenous delivery of VSV-ASMEL. This regimen significantly improved the overall survival of mice bearing subcutaneous B16 melanoma. Finally, the triple combination immunotherapy significantly enhanced survival of mice, with improved frequencies of durable cures (versus mono- or dual-component treatment cohorts), in association with robust Th1 and Th17 immune responses against tumor antigens (98).

In our recent study, we explored the efficacy of combined therapy using oncolytic VACV and anti-PD-L1 Ab in murine colon and ovarian cancer models (118). We hypothesized that an oncolytic VACV would elicit antitumor adaptive immune response and attract $\mathrm{T}$ cells into the tumor, with the resulting inflammation promoting PD-L1 expression in both cancer and immune cells, making the TME susceptible to subsequent treatment with the anti-PD-L1 antagonist $\mathrm{Ab}$. We determined that the combination immunotherapy facilitated tumor infiltration of effector $\mathrm{CD}^{+}$and $\mathrm{CD}^{+} \mathrm{T}$ cells (expressing IFN- $\gamma$, ICOS, granzyme $\mathrm{B}$, and perforin), while reducing the prevalence of $\mathrm{PD}-\mathrm{L} 1^{+}$cells and exhausted PD- $1^{+} \mathrm{CD} 8^{+}$TIL in the TME. The combination protocol also resulted in superior antitumor efficacy (versus the component monotherapies) and extended overall survival. We predict that these combination OV/immune checkpoint blockade-based immunotherapies will expand the use of checkpoint inhibition to a much wider population of cancer patients (118).

\section{CLINICAL STUDIES WITH OVs}

Starting in the year 2000, a variety of OVs have been tested in clinical trials. Many phase I studies with a variety of OV have been conducted, mostly dealing with safety and feasibility issues. Some OVs have been tested in phase II or beyond. Since 2010, nine phase II/III clinical trials employing four types of OVs have been reported (Table 1). In this section, we will focus on those OVs in phase II trials and then briefly discuss the OVs with completed phase III trials, and two phase Ib clinical studies combining T-VEC with immune checkpoint blockade in patients with advanced melanoma.

Two oncolytic HSVs have now been tested in four phase II trials treating patients with three different types of cancer. In the first trial, NV1020 was evaluated in patients with pretreated refractory metastatic colorectal cancer, where treatment was observed to stabilize liver metastases with minimal toxicity (119). In a second trial, Kaufman et al. assessed local and systemic immune responses after T-VEC was injected directly into melanoma lesions. They determined that (i) established tumors contained elevated levels of Treg, suppressor T cells (Ts), and MDSC at baseline and (ii) T-VEC treatment enhanced local and systemic antigen-specific $\mathrm{T}$ cell responses in association with decreased levels of Treg, Ts, and MDSC in those patients who exhibited objective clinical responses to therapy (66). In a third study, T-VEC was combined with radiotherapy and cisplatin for the treatment of patients with untreated stage III/IV squamous cell carcinoma of the head and neck (SCCHN) (120). Finally, Kaufman and others compared the efficacy of intratumorally delivered T-VEC versus non-injected non-visceral or visceral 
TABLE 1 | Phase II clinical trials in cancer patients with oncolytic viruses (OVs) (from year 2010 to current).

\begin{tabular}{|c|c|c|c|c|c|c|}
\hline OV & $\begin{array}{l}\text { Combination or } \\
\text { others }\end{array}$ & $\begin{array}{l}\text { Cancer type (patient } \\
\text { number) }\end{array}$ & Primary endpoints & \multicolumn{2}{|c|}{ Clinical responses } & Reference \\
\hline $\begin{array}{l}\text { Herpes simplex } \\
\text { virus (HSV) } \\
\text { (NV1020) }\end{array}$ & & $\begin{array}{l}\text { Refractory metastatic } \\
\text { colorectal cancer } \\
\text { (19 in phase II) }\end{array}$ & Toxicity and efficacy & \multicolumn{2}{|c|}{$50 \%$ patients with stable disease } & $\begin{array}{l}\text { Geevarghese } \\
\text { et al. (119) }\end{array}$ \\
\hline HSV (T-VEC) & & $\begin{array}{l}\text { Metastatic melanoma } \\
\text { patients (50) }\end{array}$ & $\begin{array}{l}\text { Local and distant } \\
\text { antitumor immunity }\end{array}$ & & $\begin{array}{l}\text { Elevated levels of regulatory T cells (Tregs), } \\
\text { suppressor T cells (Ts), and myeloid-derived } \\
\text { suppressor cell (MDSC) within established } \\
\text { tumors } \\
\text { Direct injection of T-VEC induces local and } \\
\text { systemic antigen-specific T cell responses } \\
\text { and decreases Treg, Ts, and MDSC in } \\
\text { patients exhibiting therapeutic responses }\end{array}$ & Kaufman et al. (66) \\
\hline HSV (T-VEC) & $\begin{array}{l}\text { Radiotherapy + } \\
\text { cisplatin }\end{array}$ & $\begin{array}{l}\text { Untreated stage III/IV } \\
\text { squamous cell carcinoma } \\
\text { of the head and neck (17) }\end{array}$ & Safety and efficacy & $\begin{array}{l}(1) \\
(2) \\
(3)\end{array}$ & $\begin{array}{l}82 \% \text { patients showed tumor responses } \\
\text { by RECIST } \\
93 \% \text { pathologic complete regression } \\
\text { DFS } 82 \% \text { at } 29 \text { months }\end{array}$ & Harrigton et al. (120) \\
\hline HSV (T-VEC) & $\begin{array}{l}\text { Systemic versus } \\
\text { local responses }\end{array}$ & $\begin{array}{l}\text { Stage IIIc or IV } \\
\text { melanoma (50) }\end{array}$ & $\begin{array}{l}\text { Comparison of efficacy } \\
\text { in directly injected } \\
\text { lesions, and uninjected } \\
\text { non-visceral } \\
\text { and visceral lesions }\end{array}$ & (1) & $\begin{array}{l}\text { Lesions directly injected: } 67 \% \text { decreased } \\
\text { in size; } 46 \% \text { completely resolved } \\
\text { Uninjected non-visceral lesions: } 41 \% \\
\text { decreased in size; } 30 \% \text { completely resolved }\end{array}$ & Kaufman et al. (121) \\
\hline $\begin{array}{l}\text { Reovirus (RT3D; } \\
\text { same } \\
\text { as Reolysin }{ }^{\circledast} \text { ) }\end{array}$ & $\begin{array}{l}\text { Carboplatin + } \\
\text { paclitaxel }\end{array}$ & $\begin{array}{l}\text { Advanced } \\
\text { malignancies (31) }\end{array}$ & Safety and efficacy & & $\begin{array}{l}\text { No dose-limiting toxicity } \\
\text { One complete response, } 6 \text { partial responses, } \\
9 \text { stable disease, and } 8 \text { disease progression }\end{array}$ & $\begin{array}{l}\text { Karapanagiotou } \\
\text { et al. (122) }\end{array}$ \\
\hline $\begin{array}{l}\text { Reovirus } \\
\left.\text { (Reolysin }{ }^{\circledR}\right)\end{array}$ & & $\begin{array}{l}\text { Advanced } \\
\text { melanoma (21) }\end{array}$ & Safety and efficacy & $\begin{array}{l}(1) \\
(2) \\
(3)\end{array}$ & $\begin{array}{l}\text { Viral replication }(2 / 21) \\
\text { No objective response } \\
\text { Median time to progression and survival } \\
\text { were } 45 \text { and } 165 \text { days }\end{array}$ & Galanis et al. (123) \\
\hline $\begin{array}{l}\text { Reovirus } \\
\text { (Reolysin; } \\
\text { Pelareorep) }\end{array}$ & $\begin{array}{l}\text { Paclitaxel/ } \\
\text { carboplatin }\end{array}$ & $\begin{array}{l}\text { Metastatic pancreatic } \\
\text { adenocarcinoma } \\
(\operatorname{arm~A,~} n=36)\end{array}$ & & $\begin{array}{l}(1) \\
(2) \\
(3)\end{array}$ & $\begin{array}{l}\text { The majority of PFS time was without } \\
\text { toxicity or progression ( } 4.3 \text { months) } \\
\text { Patient immunophenotype appeared } \\
\text { important } \\
\text { Overall, pelareorep was safe but does } \\
\text { not improve PFS }\end{array}$ & Noonan et al. (124) \\
\hline $\mathrm{AdV}$ & Radiation & $\begin{array}{l}\text { Intermediate-risk prostate } \\
\text { cancer -(21 in the arm) }\end{array}$ & $\begin{array}{l}\text { Acute ( } \leq 90 \text { days) } \\
\text { toxicity }\end{array}$ & $\begin{array}{l}\text { Whe } \\
\text { redi }\end{array}$ & $\begin{array}{l}\text { en used combined, a clinically meaningful } \\
\text { uction in positive biopsy results at } 2 \text { years }\end{array}$ & Freytag et al. (125) \\
\hline $\begin{array}{l}\text { Vaccinia virus } \\
\text { (JX-594; } \\
\text { Pexa-Vec) }\end{array}$ & & $\begin{array}{l}\text { Advanced hepatocellular } \\
\text { carcinoma }(n=30)\end{array}$ & $\begin{array}{l}\text { To determine the } \\
\text { optimal dose }\end{array}$ & (1) & $\begin{array}{l}\text { JX-594 replication and granulocyte- } \\
\text { macrophage colony-stimulating factor } \\
\text { expression preceded the induction of } \\
\text { anticancer immunity } \\
\text { Median survival of } 14.1 \text { months compared } \\
\text { to } 6.7 \text { months on the high and low dose, } \\
\text { respectively }\end{array}$ & Heo et al. (68) \\
\hline
\end{tabular}

lesions. They found that the therapeutic efficacy was greatest in the injected lesions, intermediate in non-injected non-visceral lesions, and lowest in visceral lesions (121).

Reovirus has also been evaluated in three phase II trials treating various advanced forms of cancer. Reolysin (RT3D) administered with carboplatin and paclitaxel has been evaluated for safety and efficacy in patients with SCCHN (122). The authors report no dose-limiting toxicity, with a large fraction of patients exhibiting stable disease, as well as, several PR or CR (4\%). Reolysin has also been used to treat patients with advanced-stage melanoma via intravenous delivery, where again the treatment was observed to be well tolerated, with evidence for virus replication in tumor biopsies (123). Furthermore, Reolysin has been applied alone or in combination with paclitaxel/carboplatin for the treatment of patients with metastatic pancreatic adenocarcinoma in a randomized phase II trial (124). The approach was found to be safe, although the combination therapy was not superior to carboplatin/paclitaxel alone in improving patient progression free survival.

Other OVs have also been tested in phase II clinical trials. Oncolytic AdV applied in combination with radiation has been used to treat intermediate-risk prostate cancer in a prospective randomized phase II trial (125), clinically meaningful reductions in positive biopsies noted at 2 years posttreatment. To date, the most encouraging results have been obtained in a trial using Pexa-Vec (JX-954) to treat patients with liver cancer (68), where 
coordinate viral replication and GM-CSF expression in tumors was observed, with therapy-induced antitumor immunity also being detected. In this trial, the duration of patient survival was directly related to viral dose, with a median survival of 14.1 months in the high-dose cohort versus 6.7 months in the lowdose group.

Four phase III trials involving administration of OVs have been completed or remain open to patient accrual at this time. $\mathrm{H} 101$ is a recombinant human AdV type 5 with E1B deletion (presumably) conferring conditional replication in p53-deficient cancer cells. China approved the clinical use of H101 in 2005 $\left(\right.$ Oncorine $\left.^{\circledR}\right)$. In a multicenter, open, randomized, and parallel controlled clinical study, H101 combined with chemotherapy was reported to be superior to chemotherapy alone with a good safety profile in patients with squamous cell carcinoma of head and neck and the esophagus (126). In the United States, T-VEC was used in a successfully completed phase III OPTiM study and was FDA approved for the treatment of patients with advancedstage melanoma in 2015 (127). A third OV, Pexa-Vec (JX-594), is currently being investigated in a worldwide phase III PHOCUS trial in patients with hepatocellular carcinoma. Finally, CG0070 (AdV expressing GM-CSF) is currently being evaluated in BOND2, a phase III pivotal study, examining treatment efficacy against high-grade, non-muscle invasive bladder cancer after failure to BCG therapy.

As we have discussed previously, positive clinical results were obtained from HCC patients in South Korea receiving Pexa-Vec (68). In contrast, its TRAVERSE Phase 2 study of Pexa-Vec in second-line advanced liver cancer in the United States (in 2013) did not meet its primary endpoint. It will be interesting to analyze the contradictory results in Asia and North America in greater detail. We would argue that the success of $\mathrm{OV}$, as a form of immunotherapy, critically depends on intrinsic or therapeutically inducible cancer immunogenicity. In Asia, infection with hepatitis B virus is the more common cause of HCC, while in the United States, hepatitis $\mathrm{C}$ virus (HCV) is a more common etiologic agent. HCV may also possess a higher capacity to evade the immune system (128). As of today, we still do not have an effective vaccine against $\mathrm{HCV}$, and we would hypothesize that liver cancers (mostly HCC) resulting from chronic HCV infection may be generally less immunogenic than those tumors caused by HBV infection.

We have been developing the WR strain VACV as an OV (129). Phase I clinical trials with vvDD, a double viral genes-deleted tumor-selective OV, have now been completed. The first-inhuman dose-escalation trial of vvDD was performed in 16 patients with advanced-stage solid tumors, predominantly colorectal cancer (130). Viral dose escalation, delivered intratumorally, proceeded without dose-limiting toxicities, up to a maximum feasible dose at 3.0e9 pfu. Viral replication in tumors was reproducibly observed, with virus recovered from both injected and non-injected tumors. In summary, vvDD delivered intratumorally was well tolerated in patients, with viral administration leading to selective infection of injected and non-injected tumors, with coordinate antitumor activity noted. In a second trial, we delivered the virus intravenously into cancer patients (131). Again, we observed no dose-limiting toxicities or treatment-related severe adverse events. Viral genome DNA was detectable in patient blood shortly after virus administration, with prolonged viral replication detected in tumor tissues isolated from two patients. Viral replication was not found in non-tumor tissues, with the exception of sites of injury. It is worth noting that the best clinical responses were observed in the two patients with melanoma in these two trials. This could reflect the consensus that melanoma is a particularly immunogenic type of cancer (and possibly preferred target for immunotherapy (132)) and/or that skin is the normal target tissue for infection by VACV (possibly making it easier for VACV to induce ICD in cutaneous forms of cancer).

Szalay, Fong, and others have also been developing LIVP strain-derived oncolytic VACV GLV-1h68 (commercial name: GL-ONC1) (133). Multisite clinical studies have demonstrated a favorable safety profile and hinted at the potential use of GL-ONC1 as an effective therapeutic agent (e.g., ASCO Annual Meeting 2015). Two ongoing phase I clinical trials are currently evaluating i.v.-administered GL-ONC1 along with concurrent chemoradiotherapy for patients with locoregionally advanced head and neck carcinoma and intrapleural administration of GL-ONC1 for patients with malignant pleural effusion.

At this time, the most exciting clinical studies appear to be those combining OV with immune checkpoint blockade. A phase Ib study using T-VEC with ipilimumab, an anti-CTLA-4 antagonist $\mathrm{Ab}$, in patients with unresectable stage IIIb/IV melanoma has been recently reported (134). Nineteen patients were included in the safety analysis. No dose-limiting toxicities were observed. The objective response rate reached $50 \%$, with $44 \%$ of patients exhibiting durable responses lasting $\geq 6$ months. The conclusion of the study was that the combined treatment had a tolerable safety profile and appeared to have greater efficacy than either monotherapy.

Pembrolizumab is an anti-PD-1 antagonist Ab. Previous clinical studies have shown that clinical administration of this $\mathrm{Ab}$ leads to greater progression-free survival and overall survival than ipilimumab in melanoma patients, suggesting that a combination of T-VEC with pembrolizumab might be more effective than the combination with ipilimumab. An ongoing phase I-III study was designed to explore this combination for patients with unresected melanoma (NCT02263508) (135). In the phase Ib study of 21 patients, the reported ORR was $57 \%$, with $24 \%$ of patients with confirmed complete response. The disease control rate was $71 \%$. A phase III randomized, double-blind, placebo-controlled trial (MASTERKEY-265) is now planned for 660 patients with unresectable state IIIb/IV melanoma.

\section{CONCLUSION AND PERSPECTIVES}

The TME in the setting of advanced-stage cancers is highly immunosuppressive (136). As we and others have previously suggested, this immunosuppressive property poses a doubleedge sword in consideration of OV-based immunotherapy. Such suppression limits immune regulation of viral replication in support of direct oncolysis, but it represents a major impediment to the development, targeting and operational integrity of protective antitumor immunity that appears crucial to the 
durable clinical success of OV-based interventional strategies. How we manipulate this delicate balance may likely determine the optimal benefits that can be achieved using such treatment modalities in the clinic. Notably, administration of OVs often leads to ICD of cancer cells, a process in which dying tumor cells expose/release multiple potent danger signals (signal 0) and pro-inflammatory cytokines (signal 3), while in some cases, coordinately upregulating their expression of MHC class I and II antigens. ICD in the TME begets efficient tumor antigen-cross presentation (signals 1 and 2) by tumor-associated DC that serve as the instigators of robust type- $1 \mathrm{~T}$ cell responses capable of limiting tumor growth/metastasis. Combinatorial OV-based approaches allow for the fine tuning of the immune microenvironment within tumors, leading to removal of suppressive cells/ factors and the recruitment and maintenance of therapeutically induced antitumor immune cells. Such combinational approaches, incorporating chemotherapeutic drugs, vaccines, or adoptive immune cell therapies, hold great clinical promise in optimizing the therapeutic potential of OV-based interventional approaches.

There also remains great need to further investigate mechanisms underlying patient resistance to oncolytic immunotherapy and any OV-associated toxicities. There are primary, adaptive, and acquired resistance to OV-mediated and other cancer immunotherapy (137). As our understanding for mechanisms of resistance continues to improve, we will be in position to rationally design combinatorial strategies to safely overcome such resistance. Our recent study combining OV and anti-PD-L1 represents one such study (118). There is also need to define biomarkers associated with clinical response (or resistance, toxicity) to treatment with oncolytic immunotherapy. Only a few studies have been published in this area of research to date. In this regard, serum HMGB1 has been shown to be a predictive and prognostic marker for successful oncolytic immunotherapy with AdV (138). In another study, immunoglobulin-like transcript 2 has been identified as a biomarker of therapeutic response to oncolytic VACV (13). These types of studies may enable us to better predict OV-based treatment outcomes in future clinical trials.

A number of hurdles remain that limit wide-spread use of OV-based therapies in the cancer setting. The first hurdle is the inability of $\mathrm{OV}$ to efficiently deliver and propagate throughout the entire tumor and to infect cancer cells that are at extended distances from the site of virus injection or from the original site of infection site after systemic delivery, which limits the ability of this approach to achieve consistent therapeutic responses in patients with disseminated disease. The tumor matrix also hinders virus diffusion throughout a given lesion. Some suggested means to circumvent this limitation have been offered. For example, the engineered overexpression of matrix metalloproteinases- 1 and -8 significantly depletes tumor-associated sulfated glycosaminoglycans, resulting in increased tumor perfusion and greater distribution of injected virus in association with improved therapeutic efficacy (139). Similarly, enforced expression of hyaluronidase by OV led to improved virus spread throughout the tumor and to greater therapeutic benefit (140). Losartan, an angiotensin II receptor antagonist, appears capable of enhancing the distribution and efficacy of nanomedicines, including OVs (141). Another reason for the low efficiency of virus distribution throughout the tumor reflects the relatively high interstitial fluid pressure of the TME (142). In this regard, blood flow may affect the intratumoral extravasation of systemically delivered OVs. Indeed, one recent study demonstrated that perfusion pressure greatly affects the intratumoral extravasation of OVs (143). Antiangiogenic therapies, through their induction of collagen degradation, can also enhance intratumoral distribution of oncolytic AdV (144). Clearly, additional investigations will be required to further improve upon tumor uptake and intralesional distribution of OVs to yield more effective cancer therapies.

A second hurdle involves the need to develop a broad repertoire of therapeutic immune cells that circulate systemically to impact disseminated disease, which typically evolves over time (145). Such timing can be adversely affected by antiviral immunity that may clear the OV prematurely, thus reducing therapeutic efficacy. For example, HSV-mediated oncolytic virotherapy for glioblastoma is often improved with the suppression of innate immune responses, leading to increased viral replication and subsequent oncolysis $(146,147)$. However, the boosting of antiviral immunity has also been shown to be required for efficient OV-mediated therapy benefits in some tumor models $(7,148,149)$ and can play a "helper" role in the evolution of adaptive antitumor immunity elicited by $\mathrm{OV}$, with the ultimate therapeutic efficacy requiring a delicate balance of the avidity, potency, and timing of the immune response directed against the virus versus the tumor (150).

A third hurdle reflects toxicities associated with OVs. In patients receiving Imlygic (T-VEC), adverse reactions, including fatigue (50\%), chills, pyrexia, nausea, influenza-like illness, injection-site pain, and vomiting, occurred in over $20 \%$ of treated patients, with the most common grade $3 / 4$ adverse reaction being cellulitis (127). Given the use of a live virus, Imlygic can cause life-threatening dissemination of herpetic infections in immunocompromised patients. As a result, the use of T-VEC is contraindicated in immunocompromised patients and in pregnant women. We have recently evaluated OV derived from the WR strain of VACV (vvDD), and based on our findings, patients with actively healing wounds, or those with acute inflammatory conditions involving the skin or oral mucosa, should be excluded from using this OV (131). It also should not be used by immunocompromised patients.

Finally, accumulating evidence suggests that microbiota play an important role in the initiation, progression, and dissemination of cancer, not only at epithelial barriers but also in sterile tissues. Perhaps more importantly, barrier tissue microbiota can modulate cancer patient response to interventional therapy (including immunotherapy), as well as, patient adverse events to therapy (151). In this regard, it will be critical to further study the relationship between OV and microbiota in the host to better predict the likelihood of therapeutic efficacy versus treatmentassociated toxicity.

In summary, it is indeed an exciting time to work in field of cancer immunotherapy. By combining with other forms of cancer immunotherapy, especially modulation of immune checkpoint pathways (impacting signal 2) and adoptive cell therapies, 
the future appears bright for the effective use of OV-based immunotherapy in the cancer setting.

\section{AUTHOR CONTRIBUTIONS}

ZG collected and read relevant papers and designed and drafted the manuscript. WS revised and polished the whole manuscript. All other authors have made suggestions to the manuscript. All authors have read and approved the final manuscript.

\section{REFERENCES}

1. Breitbach CJ, Paterson JM, Lemay CG, Falls TJ, McGuire A, Parato KA, et al. Targeted inflammation during oncolytic virus therapy severely compromises tumor blood flow. Mol Ther (2007) 15:1686-93. doi:10.1038/ sj.mt.6300215

2. Liu TC, Hwang T, Park BH, Bell J, Kirn DH. The targeted oncolytic poxvirus JX-594 demonstrates antitumoral, antivascular, and anti-HBV activities in patients with hepatocellular carcinoma. Mol Ther (2008) 16:1637-42. doi:10.1038/mt.2008.143

3. Breitbach CJ, Arulanandam R, De Silva N, Thorne SH, Patt R, Daneshmand M, et al. Oncolytic vaccinia virus disrupts tumor-associated vasculature in humans. Cancer Res (2013) 73:1265-75. doi:10.1158/0008-5472.CAN12-2687

4. Kirn D. Oncolytic virotherapy for cancer with the adenovirus dl1520 (Onyx-015): results of phase I and II trials. Expert Opin Biol Ther (2001) 1:525-38. doi:10.1517/14712598.1.3.525

5. Diaz RM, Galivo F, Kottke T, Wongthida P, Qiao J, Thompson J, et al. Oncolytic immunovirotherapy for melanoma using vesicular stomatitis virus. Cancer Res (2007) 67:2840-8. doi:10.1158/0008-5472.CAN-06-3974

6. Prestwich RJ, Errington F, Ilett EJ, Morgan RS, Scott KJ, Kottke T, et al. Tumor infection by oncolytic reovirus primes adaptive antitumor immunity. Clin Cancer Res (2008) 14:7358-66. doi:10.1158/1078-0432.CCR-08-0831

7. Sobol PT, Boudreau JE, Stephenson K, Wan Y, Lichty BD, Mossman KL. Adaptive antiviral immunity is a determinant of the therapeutic success of oncolytic virotherapy. Mol Ther (2011) 19:335-44. doi:10.1038/mt.2010.264

8. Prestwich RJ, Harrington KJ, Pandha HS, Vile RG, Melcher AA, Errington F. Oncolytic viruses: a novel form of immunotherapy. Expert Rev Anticancer Ther (2008) 8:1581-8. doi:10.1586/14737140.8.10.1581

9. Bhat R, Dempe S, Dinsart C, Rommelaere J. Enhancement of NK cell antitumor responses using an oncolytic parvovirus. Int J Cancer (2011) 128:908-19. doi:10.1002/ijc.25415

10. Pesonen S, Diaconu I, Kangasniemi L, Ranki T, Kanerva A, Pesonen SK, et al. Oncolytic immunotherapy of advanced solid tumors with a CD40Lexpressing replicating adenovirus: assessment of safety and immunologic responses in patients. Cancer Res (2012) 72:1621-31. doi:10.1158/0008-5472. CAN-11-3001

11. Ady JW, Heffner J, Mojica K, Johnsen C, Belin LJ, Love D, et al. Oncolytic immunotherapy using recombinant vaccinia virus GLV-1h68 kills sorafenib-resistant hepatocellular carcinoma efficiently. Surgery (2014) 156:263-9. doi:10.1016/j. surg.2014.03.031

12. Guo ZS, Liu Z, Bartlett DL. Oncolytic immunotherapy: dying the right way is a key to eliciting potent antitumor immunity. Front Oncol (2014) 4:74. doi:10.3389/fonc.2014.00074

13. Zloza A, Kim DW, Kim-Schulze S, Jagoda MC, Monsurro V, Marincola FM, et al. Immunoglobulin-like transcript 2 (ILT2) is a biomarker of therapeutic response to oncolytic immunotherapy with vaccinia viruses. J Immunother Cancer (2014) 2:1. doi:10.1186/2051-1426-2-1

14. Kaufman HL, Kohlhapp FJ, Zloza A. Oncolytic viruses: a new class of immunotherapy drugs. Nat Rev Drug Discov (2015) 14:642-62. doi:10.1038/ nrd4663

15. Kelly E, Russell SJ. History of oncolytic viruses: genesis to genetic engineering. Mol Ther (2007) 15:651-9. doi:10.1038/sj.mt.6300108

16. Martuza RL, Malick A, Markert JM, Ruffner KL, Coen DM. Experimental therapy of human glioma by means of a genetically engineered virus mutant. Science (1991) 252:854-6. doi:10.1126/science.1851332

\section{FUNDING}

The authors received no specific funding for writing this review article. The original research from our own groups discussed in this review has been supported by the grants P01CA132714, R01CA155925, and R21CA205727 from the National Institutes of Health. MF is supported by a fellowship from German Research Foundation. Additional support was provided by David C. Koch Regional Cancer Therapy Center.

17. Lin E, Nemunaitis J. Oncolytic viral therapies. Cancer Gene Ther (2004) 11:643-64. doi:10.1038/sj.cgt.7700733

18. Yoon SS, Nakamura H, Carroll NM, Bode BP, Chiocca EA, Tanabe KK. An oncolytic herpes simplex virus type 1 selectively destroys diffuse liver metastases from colon carcinoma. FASEB J (2000) 14:301-11.

19. Liu TC, Hallden G, Wang Y, Brooks G, Francis J, Lemoine N, et al. An E1B-19 kDa gene deletion mutant adenovirus demonstrates tumor necrosis factor-enhanced cancer selectivity and enhanced oncolytic potency. Mol Ther (2004) 9:786-803. doi:10.1016/j.ymthe.2004.03.017

20. Guo ZS, Naik A, O’Malley ME, Popovic P, Demarco R, Hu Y, et al. The enhanced tumor selectivity of an oncolytic vaccinia lacking the host range and antiapoptosis genes SPI-1 and SPI-2. Cancer Res (2005) 65:9991-8. doi:10.1158/0008-5472.CAN-05-1630

21. Puhlmann M, Gnant M, Brown CK, Alexander HR, Bartlett DL. Thymidine kinase-deleted vaccinia virus expressing purine nucleoside phosphorylase as a vector for tumor-directed gene therapy. Hum Gene Ther (1999) 10:649-57. doi:10.1089/10430349950018724

22. Ziauddin MF, Guo ZS, O’Malley ME, Austin F, Popovic PJ, Kavanagh MA, et al. TRAIL gene-armed oncolytic poxvirus and oxaliplatin can work synergistically against colorectal cancer. Gene Ther (2010) 17:550-9. doi:10.1038/ gt. 2010.5

23. Timiryasova TM, Li J, Chen B, Chong D, Langridge WH, Gridley DS, et al. Antitumor effect of vaccinia virus in glioma model. Oncol Res (1999) 11:133-44.

24. Heiber JF, Barber GN. Vesicular stomatitis virus expressing tumor suppressor p53 is a highly attenuated, potent oncolytic agent. J Virol (2011) 85:10440-50. doi:10.1128/JVI.05408-11

25. Toda M, Rabkin SD, Kojima H, Martuza RL. Herpes simplex virus as an in situ cancer vaccine for the induction of specific anti-tumor immunity. Hum Gene Ther (1999) 10:385-93. doi:10.1089/10430349950018832

26. Li H, Dutuor A, Tao L, Fu X, Zhang X. Virotherapy with a type 2 herpes simplex virus-derived oncolytic virus induces potent antitumor immunity against neuroblastoma. Clin Cancer Res (2007) 13:316-22. doi:10.1158/10780432.CCR-06-1625

27. Li H, Zeng Z, Fu X, Zhang X. Coadministration of a herpes simplex virus-2 based oncolytic virus and cyclophosphamide produces a synergistic antitumor effect and enhances tumor-specific immune responses. Cancer Res (2007) 67:7850-5. doi:10.1158/0008-5472.CAN-07-1087

28. Kurooka M, Kaneda Y. Inactivated Sendai virus particles eradicate tumors by inducing immune responses through blocking regulatory T cells. Cancer Res (2007) 67:227-36. doi:10.1158/0008-5472.CAN-06-1615

29. Liu BL, Robinson M, Han ZQ, Branston RH, English C, Reay P, et al. ICP34.5 deleted herpes simplex virus with enhanced oncolytic, immune stimulating, and anti-tumour properties. Gene Ther (2003) 10:292-303. doi:10.1038/ sj.gt.3301885

30. Bartlett DL, Liu Z, Sathaiah M, Ravindranathan R, Guo Z, He Y, et al. Oncolytic viruses as therapeutic cancer vaccines. Mol Cancer (2013) 12:103. doi:10.1186/1476-4598-12-103

31. Lichty BD, Breitbach CJ, Stojdl DF, Bell JC. Going viral with cancer immunotherapy. Nat Rev Cancer (2014) 14:559-67. doi:10.1038/nrc3770

32. Janeway C. Immunogenicity signals $1,2,3 \ldots$ and 0. Immunol Today (1989) 10:283-6. doi:10.1016/0167-5699(89)90081-9

33. Matzinger P. Tolerance, danger, and the extended family. Annu Rev Immunol (1994) 12:991-1045. doi:10.1146/annurev.iy.12.040194.005015

34. Matzinger P. The danger model: a renewed sense of self. Science (2002) 296:301-5. doi:10.1126/science.1071059 
35. Kepp O, Senovilla L, Vitale I, Vacchelli E, Adjemian S, Agostinis P, et al. Consensus guidelines for the detection of immunogenic cell death. Oncoimmunology (2014) 3:e955691. doi:10.4161/21624011.2014.955691

36. Casares N, Pequignot MO, Tesniere A, Ghiringhelli F, Roux S, Chaput N, et al. Caspase-dependent immunogenicity of doxorubicin-induced tumor cell death. J Exp Med (2005) 202:1691-701. doi:10.1084/jem.20050915

37. Tesniere A, Apetoh L, Ghiringhelli F, Joza N, Panaretakis T, Kepp O, et al. Immunogenic cancer cell death: a key-lock paradigm. Curr Opin Immunol (2008) 20:504-11. doi:10.1016/j.coi.2008.05.007

38. Inoue H, Tani K. Multimodal immunogenic cancer cell death as a consequence of anticancer cytotoxic treatments. Cell Death Differ (2014) 21:39-49. doi:10.1038/cdd.2013.84

39. Aaes TL, Kaczmarek A, Delvaeye T, De Craene B, De Koker S, Heyndrickx L, et al. Vaccination with necroptotic cancer cells induces efficient anti-tumor immunity. Cell Rep (2016) 15:274-87. doi:10.1016/j.celrep.2016.03.037

40. Galluzzi L, Buque A, Kepp O, Zitvogel L, Kroemer G. Immunogenic cell death in cancer and infectious disease. Nat Rev Immunol (2017) 17:97-111. doi:10.1038/nri.2016.107

41. Zitvogel L, Galluzzi L, Smyth MJ, Kroemer G. Mechanism of action of conventional and targeted anticancer therapies: reinstating immunosurveillance. Immunity (2013) 39:74-88. doi:10.1016/j.immuni.2013.06.014

42. Adkins I, Fucikova J, Garg AD, Agostinis P, Spisek R. Physical modalities inducing immunogenic tumor cell death for cancer immunotherapy. Oncoimmunology (2014) 3:e968434. doi:10.4161/21624011.2014.968434

43. Zhou H, Forveille S, Sauvat A, Yamazaki T, Senovilla L, Ma Y, et al. The oncolytic peptide LTX-315 triggers immunogenic cell death. Cell Death Dis (2016) 7:e2134. doi:10.1038/cddis.2016.47

44. Kepp O, Senovilla L, Galluzzi L, Panaretakis T, Tesniere A, Schlemmer F, et al. Viral subversion of immunogenic cell death. Cell Cycle (2009) 8:860-9. doi:10.4161/cc.8.6.7939

45. Miyamoto S, Inoue H, Nakamura T, Yamada M, Sakamoto C, Urata Y, et al. Coxsackievirus B3 is an oncolytic virus with immunostimulatory properties that is active against lung adenocarcinoma. Cancer Res (2012) 72:2609-21. doi:10.1158/0008-5472.CAN-11-3185

46. Boozari B, Mundt B, Woller N, Strüver N, Gürlevik E, Schache P, et al. Antitumoural immunity by virus-mediated immunogenic apoptosis inhibits metastatic growth of hepatocellular carcinoma. Gut (2010) 59:1416-26. doi:10.1136/gut.2009.196519

47. Lindenmann J, Klein PA. Viral oncolysis: increased immunogenicity of host cell antigen associated with influenza virus. J Exp Med (1967) 126:93-108. doi:10.1084/jem.126.1.93

48. Workenhe ST, Simmons G, Pol JG, Lichty BD, Halford WP, Mossman KL. Immunogenic HSV-mediated oncolysis shapes the antitumor immune response and contributes to therapeutic efficacy. Mol Ther (2014) 22:123-31. doi: $10.1038 / \mathrm{mt} .2013 .238$

49. Takasu A, Masui A, Hamada M, Imai T, Iwai S, Yura Y. Immunogenic cell death by oncolytic herpes simplex virus type 1 in squamous cell carcinoma cells. Cancer Gene Ther (2016) 23:107-13. doi:10.1038/cgt.2016.8

50. Donnelly OG, Errington-Mais F, Steele L, Hadac E, Jennings V, Scott K, et al. Measles virus causes immunogenic cell death in human melanoma. Gene Ther (2013) 20:7-15. doi:10.1038/gt.2011.205

51. Koks CA, Garg AD, Ehrhardt M, Riva M, Vandenberk L, Boon L, et al. Newcastle disease virotherapy induces long-term survival and tumor-specific immune memory in orthotopic glioma through the induction of immunogenic cell death. Int J Cancer (2015) 136:E313-25. doi:10.1002/ijc.29202

52. Matveeva OV, Guo ZS, Shabalina SA, Chumakov PM. Oncolysis by paramyxoviruses: multiple mechanisms contribute to therapeutic efficiency. Mol Ther Oncolytics (2015) 2:15011. doi:10.1038/mto.2015.11

53. Colunga AG, Laing JM, Aurelian L. The HSV-2 mutant DeltaPK induces melanoma oncolysis through nonredundant death programs and associated with autophagy and pyroptosis proteins. Gene Ther (2010) 17:315-27. doi:10.1038/ gt.2009.126

54. Bollino D, Colunga A, Li B, Aurelian L. DeltaPK oncolytic activity includes modulation of the tumour cell milieu. J Gen Virol (2016) 97:496-508. doi:10.1099/ jgv.0.000353

55. Errington F, Steele L, Prestwich R, Harrington KJ, Pandha HS, Vidal L, et al. Reovirus activates human dendritic cells to promote innate antitumor immunity. J Immunol (2008) 180:6018-26. doi:10.4049/jimmunol.180.9.6018
56. Boudreau JE, Bridle BW, Stephenson KB, Jenkins KM, Brunellière J, Bramson JL, et al. Recombinant vesicular stomatitis virus transduction of dendritic cells enhances their ability to prime innate and adaptive antitumor immunity. Mol Ther (2009) 17:1465-72. doi:10.1038/mt.2009.95

57. Yammani RD, Pejawar-Gaddy S, Gurley TC, Weimer ET, Hiltbold EM, Alexander-Miller MA. Regulation of maturation and activating potential in CD8+ versus CD8- dendritic cells following in vivo infection with vaccinia virus. Virology (2008) 378:142-50. doi:10.1016/j.virol.2008.05.031

58. Kilinc MO, Ehrig K, Pessian M, Minev BR, Szalay AA. Colonization of xenograft tumors by oncolytic vaccinia virus (VACV) results in enhanced tumor killing due to the involvement of myeloid cells. J Transl Med (2016) 14:340. doi:10.1186/s12967-016-1096-1

59. Moehler MH, Zeidler M, Wilsberg V, Cornelis JJ, Woelfel T, Rommelaere J, et al. Parvovirus H-1-induced tumor cell death enhances human immune response in vitro via increased phagocytosis, maturation, and cross-presentation by dendritic cells. Hum Gene Ther (2005) 16:996-1005. doi:10.1089/hum.2005.16.996

60. Gauvrit A, Brandler S, Sapede-Peroz C, Boisgerault N, Tangy F, Gregoire M. Measles virus induces oncolysis of mesothelioma cells and allows dendritic cells to cross-prime tumor-specific CD8 response. Cancer Res (2008) 68:4882-92. doi:10.1158/0008-5472.CAN-07-6265

61. Vigil A, Martinez O, Chua MA, Garcia-Sastre A. Recombinant Newcastle disease virus as a vaccine vector for cancer therapy. Mol Ther (2008) 16:1883-90. doi:10.1038/mt.2008.181

62. Galanis E, Hartmann LC, Cliby WA, Long HJ, Peethambaram PP, Barrette BA, et al. Phase I trial of intraperitoneal administration of an oncolytic measles virus strain engineered to express carcinoembryonic antigen for recurrent ovarian cancer. Cancer Res (2010) 70:875-82. doi:10.1158/ 0008-5472.CAN-09-2762

63. Bridle BW, Stephenson KB, Boudreau JE, Koshy S, Kazdhan N, Pullenayegum E, et al. Potentiating cancer immunotherapy using an oncolytic virus. Mol Ther (2010) 18:1430-9. doi:10.1038/mt.2010.98

64. Wongthida P, Diaz RM, Pulido C, Rommelfanger D, Galivo F, Kaluza K, et al. Activating systemic T-cell immunity against self tumor antigens to support oncolytic virotherapy with vesicular stomatitis virus. Hum Gene Ther (2011) 22:1343-53. doi:10.1089/hum.2010.216

65. Heinzerling L, Künzi V, Oberholzer PA, Kündig T, Naim H, Dummer R. Oncolytic measles virus in cutaneous T-cell lymphomas mounts antitumor immune responses in vivo and targets interferon-resistant tumor cells. Blood (2005) 106:2287-94. doi:10.1182/blood-2004-11-4558

66. Kaufman HL, Kim DW, DeRaffele G, Mitcham J, Coffin RS, Kim-Schulze S. Local and distant immunity induced by intralesional vaccination with an oncolytic herpes virus encoding GM-CSF in patients with stage IIIc and IV melanoma. Ann Surg Oncol (2010) 17:718-30. doi:10.1245/s10434-0090809-6

67. Cerullo V, Pesonen S, Diaconu I, Escutenaire S, Arstila PT, Ugolini M, et al. Oncolytic adenovirus coding for granulocyte macrophage colonystimulating factor induces antitumoral immunity in cancer patients. Cancer Res (2010) 70:4297-309. doi:10.1158/0008-5472.CAN-09-3567

68. Heo J, Reid T, Ruo L, Breitbach CJ, Rose S, Bloomston M, et al. Randomized dose-finding clinical trial of oncolytic immunotherapeutic vaccinia JX-594 in liver cancer. Nat Med (2013) 19:329-36. doi:10.1038/nm.3089

69. Chou J, Roizman B. The gamma 1(34.5) gene of herpes simplex virus 1 precludes neuroblastoma cells from triggering total shutoff of protein synthesis characteristic of programed cell death in neuronal cells. Proc Natl Acad Sci U S A (1992) 89:3266-70. doi:10.1073/pnas.89.8.3266

70. Goldsmith K, Chen W, Johnson DC, Hendricks RL. Infected cell protein (ICP) 47 enhances herpes simplex virus neurovirulence by blocking the CD8+ T cell response. J Exp Med (1998) 187:341-8. doi:10.1084/jem.187.3.341

71. Lapteva N, Aldrich M, Weksberg D, Rollins L, Goltsova T, Chen SY, et al. Targeting the intratumoral dendritic cells by the oncolytic adenoviral vaccine expressing RANTES elicits potent antitumor immunity. J Immunother (2009) 32:145-56. doi:10.1097/CJI.0b013e318193d31e

72. Li J, O’Malley M, Urban J, Sampath P, Guo ZS, Kalinski P, et al. Chemokine expression from oncolytic vaccinia virus enhances vaccine therapies of cancer. Mol Ther (2011) 19:650-7. doi:10.1038/mt.2010.312

73. Liu Z, Ravindranathan R, Li J, Kalinski P, Guo ZS, Bartlett DL. CXCL11-armed oncolytic poxvirus elicits potent antitumor immunity and shows enhanced 
therapeutic efficacy. Oncoimmunology (2016) 5:e1091554. doi:10.1080/ 2162402X.2015.1091554

74. Francis L, Guo ZS, Liu Z, Ravindranathan R, Urban JA, Sathaiah M, et al. Modulation of chemokines in the tumor microenvironment enhances oncolytic virotherapy for colorectal cancer. Oncotarget (2016) 7:22174-85. doi:10.18632/oncotarget.7907

75. Kim HS, Kim-Schulze S, Kim DW, Kaufman HL. Host lymphodepletion enhances the therapeutic activity of an oncolytic vaccinia virus expressing 4-1BB ligand. Cancer Res (2009) 69:8516-25. doi:10.1158/0008-5472. CAN-09-2522

76. John LB, Howland LJ, Flynn JK, West AC, Devaud C, Duong CM, et al. Oncolytic virus and anti-4-1BB combination therapy elicits strong anti-tumor immunity against established cancer. Cancer Res (2012) 72: 1651-60. doi:10.1158/0008-5472.CAN-11-2788

77. Zamarin D, Holmgaard RB, Ricca J, Plitt T, Palese P, Sharma P, et al. Intratumoral modulation of the inducible co-stimulator ICOS by recombinant oncolytic virus promotes systemic anti-tumour immunity. Nat Commun (2017) 8:14340. doi:10.1038/ncomms14340

78. Wang X, Zhao X, Feng C, Weinstein A, Xia R, Wen W, et al. IL-36gamma transforms the tumor microenvironment and promotes type 1 lymphocyte-mediated antitumor immune responses. Cancer Cell (2015) 28:296-306. doi:10.1016/j.ccell.2015.07.014

79. Ilkow CS, Marguerie M, Batenchuk C, Mayer J, Ben Neriah D, Cousineau S, et al. Reciprocal cellular cross-talk within the tumor microenvironment promotes oncolytic virus activity. Nat Med (2015) 21:530-6. doi:10.1038/ nm. 3848

80. Arulanandam R, Batenchuk C, Angarita FA, Ottolino-Perry K, Cousineau S, Mottashed A, et al. VEGF-mediated induction of PRD1-BF1/Blimp1 expression sensitizes tumor vasculature to oncolytic virus infection. Cancer Cell (2015) 28:210-24. doi:10.1016/j.ccell.2015.06.009

81. Wojton J, Kaur B. Impact of tumor microenvironment on oncolytic viral therapy. Cytokine Growth Factor Rev (2010) 21:127-34. doi:10.1016/j.cytogfr. 2010.02.014

82. Galluzzi L, Senovilla L, Zitvogel L, Kroemer G. The secret ally: immunostimulation by anticancer drugs. Nat Rev Drug Discov (2012) 11:215-33. doi: $10.1038 / \mathrm{nrd} 3626$

83. Forbes NE, Krishnan R, Diallo JS. Pharmacological modulation of antitumor immunity induced by oncolytic viruses. Front Oncol (2014) 4:191. doi:10.3389/fonc.2014.00191

84. Jiang K, Li Y, Zhu Q, Xu J, Wang Y, Deng W, et al. Pharmacological modulation of autophagy enhances Newcastle disease virus-mediated oncolysis in drug-resistant lung cancer cells. BMC Cancer (2014) 14:551. doi:10.1186/ 1471-2407-14-551

85. Workenhe ST, Pol JG, Lichty BD, Cummings DT, Mossman KL. Combining oncolytic HSV-1 with immunogenic cell death-inducing drug mitoxantrone breaks cancer immune tolerance and improves therapeutic efficacy. Cancer Immunol Res (2013) 1:309-19. doi:10.1158/2326-6066.CIR-13-0059-T

86. Muthuswamy R, Berk E, Junecko BF, Zeh HJ, Zureikat AH, Normolle D, et al. NF-kappaB hyperactivation in tumor tissues allows tumor-selective reprogramming of the chemokine microenvironment to enhance the recruitment of cytolytic T effector cells. Cancer Res (2012) 72:3735-43. doi:10.1158/00085472.CAN-11-4136

87. Muthuswamy R, Corman JM, Dahl K, Chatta GS, Kalinski P. Functional reprogramming of human prostate cancer to promote local attraction of effector CD8(+) T cells. Prostate (2016) 76:1095-105. doi:10.1002/pros.23194

88. Muthuswamy R, Wang L, Pitteroff J, Gingrich JR, Kalinski P. Combination of IFNalpha and poly-I:C reprograms bladder cancer microenvironment for enhanced CTL attraction. J Immunother Cancer (2015) 3:6. doi:10.1186/ s40425-015-0050-8

89. Kumar V, Patel S, Tcyganov E, Gabrilovich DI. The nature of myeloid-derived suppressor cells in the tumor microenvironment. Trends Immunol (2016) 37:208-20. doi:10.1016/j.it.2016.01.004

90. Mao Y, Sarhan D, Steven A, Seliger B, Kiessling R, Lundqvist A. Inhibition of tumor-derived prostaglandin-e2 blocks the induction of myeloid-derived suppressor cells and recovers natural killer cell activity. Clin Cancer Res (2014) 20:4096-106. doi:10.1158/1078-0432.CCR-14-0635

91. Walker JD, Sehgal I, Kousoulas KG. Oncolytic herpes simplex virus 1 encoding 15-prostaglandin dehydrogenase mitigates immune suppression and reduces ectopic primary and metastatic breast cancer in mice. J Virol (2011) 85:7363-71. doi:10.1128/JVI.00098-11

92. Hou W, Sampath P, Rojas JJ, Thorne SH. Oncolytic virus-mediated targeting of PGE2 in the tumor alters the immune status and sensitizes established and resistant tumors to immunotherapy. Cancer Cell (2016) 30:108-19. doi:10.1016/j.ccell.2016.05.012

93. Woller N, Gürlevik E, Ureche CI, Schumacher A, Kühnel F. Oncolytic viruses as anticancer vaccines. Front Oncol (2014) 4:188. doi:10.3389/ fonc. 2014.00188

94. Bastin D, Walsh SR, Al Saigh M, Wan YH. Capitalizing on cancer specific replication: oncolytic viruses as a versatile platform for the enhancement of cancer immunotherapy strategies. Biomedicines (2016) 4:21. doi:10.3390/ biomedicines 4030021

95. Aitken AS, Roy DG, Bourgeois-Daigneault MC. Taking a stab at cancer; oncolytic virus-mediated anti-cancer vaccination strategies. Biomedicines (2017) 5:3. doi:10.3390/biomedicines5010003

96. Bridle BW, Boudreau JE, Lichty BD, Brunellière J, Stephenson K, Koshy S, et al. Vesicular stomatitis virus as a novel cancer vaccine vector to prime antitumor immunity amenable to rapid boosting with adenovirus. Mol Ther (2009) 17:1814-21. doi:10.1038/mt.2009.154

97. Bridle BW, Clouthier D, Zhang L, Pol J, Chen L, Lichty BD, et al. Oncolytic vesicular stomatitis virus quantitatively and qualitatively improves primary CD8+ T-cell responses to anticancer vaccines. Oncoimmunology (2013) 2: e26013. doi:10.4161/onci.26013

98. Ilett E, Kottke T, Thompson J, Rajani K, Zaidi S, Evgin L, et al. Prime-boost using separate oncolytic viruses in combination with checkpoint blockade improves anti-tumour therapy. Gene Ther (2017) 24:21-30. doi:10.1038/ gt.2016.70

99. Kim SY, Kang D, Choi HJ, Joo Y, Kim JH, Song JJ. Prime-boost immunization by both DNA vaccine and oncolytic adenovirus expressing GM-CSF and shRNA of TGF-beta2 induces anti-tumor immune activation. Oncotarget (2017) 8:15858-77. doi:10.18632/oncotarget.15008

100. Lim WA, June $\mathrm{CH}$. The principles of engineering immune cells to treat cancer. Cell (2017) 168:724-40. doi:10.1016/j.cell.2017.01.016

101. Nishio N, Diaconu I, Liu H, Cerullo V, Caruana I, Hoyos V, et al. Armed oncolytic virus enhances immune functions of chimeric antigen receptormodified T cells in solid tumors. Cancer Res (2014) 74:5195-205. doi:10.1158/ 0008-5472.CAN-14-0697

102. Yu F, Wang X, Guo ZS, Bartlett DL, Gottschalk SM, Song XT. T-cell engagerarmed oncolytic vaccinia virus significantly enhances antitumor therapy. Mol Ther (2014) 22:102-11. doi:10.1038/mt.2013.240

103. Fajardo CA, Guedan S, Rojas LA, Moreno R, Arias-Badia M, de Sostoa J, et al. Oncolytic adenoviral delivery of an EGFR-targeting T-cell engager improves antitumor efficacy. Cancer Res (2017) 77:2052-63. doi:10.1158/0008-5472. CAN-16-1708

104. Magge D, Guo ZS, O’Malley ME, Francis L, Ravindranathan R, Bartlett DL. Inhibitors of $\mathrm{C} 5$ complement enhance vaccinia virus oncolysis. Cancer Gene Ther (2013) 20:342-50. doi:10.1038/cgt.2013.26

105. Evgin L, Acuna SA, Tanese de Souza C, Marguerie M, Lemay CG, Ilkow CS, et al. Complement inhibition prevents oncolytic vaccinia virus neutralization in immune humans and cynomolgus macaques. Mol Ther (2015) 23:1066-76. doi:10.1038/mt.2015.49

106. Pardoll DM. The blockade of immune checkpoints in cancer immunotherapy. Nat Rev Cancer (2012) 12:252-64. doi:10.1038/nrc3239

107. Zamarin D, Postow MA. Immune checkpoint modulation: rational design of combination strategies. Pharmacol Ther (2015) 150:23-32. doi:10.1016/ j.pharmthera.2015.01.003

108. Dias JD, Hemminki O, Diaconu I, Hirvinen M, Bonetti A, Guse K, et al. Targeted cancer immunotherapy with oncolytic adenovirus coding for a fully human monoclonal antibody specific for CTLA-4. Gene Ther (2012) 19: 988-98. doi:10.1038/gt.2011.176

109. Du T, Shi G, Li YM, Zhang JF, Tian HW, Wei YQ, et al. Tumor-specific oncolytic adenoviruses expressing granulocyte macrophage colony-stimulating factor or anti-CTLA4 antibody for the treatment of cancers. Cancer Gene Ther (2014) 21:340-8. doi:10.1038/cgt.2014.34

110. Engeland CE, Grossardt C, Veinalde R, Bossow S, Lutz D, Kaufmann JK, et al. CTLA-4 and PD-L1 checkpoint blockade enhances oncolytic measles virus therapy. Mol Ther (2014) 22:1949-59. doi:10.1038/mt.2014.160 
111. Zamarin D, Holmgaard RB, Subudhi SK, Park JS, Mansour M, Palese P, et al. Localized oncolytic virotherapy overcomes systemic tumor resistance to immune checkpoint blockade immunotherapy. Sci Transl Med (2014) 6:226ra232. doi:10.1126/scitranslmed.3008095

112. Quetglas JI, Labiano S, Aznar MÁ, Bolaños E, Azpilikueta A, Rodriguez I, et al. Virotherapy with a Semliki forest virus-based vector encoding IL12 synergizes with PD-1/PD-L1 blockade. Cancer Immunol Res (2015) 3:449-54. doi:10.1158/2326-6066.CIR-14-0216

113. Rojas JJ, Sampath P, Hou W, Thorne SH. Defining effective combinations of immune checkpoint blockade and oncolytic virotherapy. Clin Cancer Res (2015) 21:5543-51. doi:10.1158/1078-0432.CCR-14-2009

114. Woller N, Gürlevik E, Fleischmann-Mundt B, Schumacher A, Knocke S, Kloos AM, et al. Viral infection of tumors overcomes resistance to PD1-immunotherapy by broadening neoantigenome-directed T-cell responses. Mol Ther (2015) 23:1630-40. doi:10.1038/mt.2015.115

115. Kleinpeter P, Fend L, Thioudellet C, Geist M, Sfrontato N, Koerper V, et al. Vectorization in an oncolytic vaccinia virus of an antibody, a Fab and a scFv against programmed cell death -1 (PD-1) allows their intratumoral delivery and an improved tumor-growth inhibition. Oncoimmunology (2016) 5:e1220467. doi:10.1080/2162402X.2016.1220467

116. Rajani K, Parrish C, Kottke T, Thompson J, Zaidi S, Ilett L, et al. Combination therapy with reovirus and anti-PD-1 blockade controls tumor growth through innate and adaptive immune responses. Mol Ther (2016) 24:166-74. doi:10.1038/mt.2015.156

117. Shen W, Patnaik MM, Ruiz A, Russell SJ, Peng KW. Immunovirotherapy with vesicular stomatitis virus and PD-L1 blockade enhances therapeutic outcome in murine acute myeloid leukemia. Blood (2016) 127:1449-58. doi:10.1182/ blood-2015-06-652503

118. Liu Z, Ravindranathan R, Kalinski P, Guo ZS, Bartlett DL. Rational combination of oncolytic vaccinia virus and PD-L1 blockade works synergistically to enhance therapeutic efficacy. Nat Commun (2017) 8:14754. doi:10.1038/ ncomms 14754

119. Geevarghese SK, Geller DA, de Haan HA, Hörer M, Knoll AE, Mescheder A, et al. Phase I/II study of oncolytic herpes simplex virus NV1020 in patients with extensively pretreated refractory colorectal cancer metastatic to the liver. Hum Gene Ther (2010) 21:1119-28. doi:10.1089/hum.2010.020

120. Harrington KJ, Hingorani M, Tanay MA, Hickey J, Bhide SA, Clarke PM, et al. Phase I/II study of oncolytic HSV GM-CSF in combination with radiotherapy and cisplatin in untreated stage III/IV squamous cell cancer of the head and neck. Clin Cancer Res (2010) 16:4005-15. doi:10.1158/1078-0432. CCR-10-0196

121. Kaufman HL, Amatruda T, Reid T, Gonzalez R, Glaspy J, Whitman E, et al. Systemic versus local responses in melanoma patients treated with talimogene laherparepvec from a multi-institutional phase II study. J Immunother Cancer (2016) 4:12. doi:10.1186/s40425-016-0116-2

122. Karapanagiotou EM, Roulstone V, Twigger K, Ball M, Tanay M, Nutting C, et al. Phase I/II trial of carboplatin and paclitaxel chemotherapy in combination with intravenous oncolytic reovirus in patients with advanced malignancies. Clin Cancer Res (2012) 18:2080-9. doi:10.1158/1078-0432.CCR-11-2181

123. Galanis E, Markovic SN, Suman VJ, Nuovo GJ, Vile RG, Kottke TJ, et al. Phase II trial of intravenous administration of Reolysin ${ }^{\star}$ (Reovirus serotype-3-dearing strain) in patients with metastatic melanoma. Mol Ther (2012) 20:1998-2003. doi:10.1038/mt.2012.146

124. Noonan AM, Farren MR, Geyer SM, Huang Y, Tahiri S, Ahn D, et al. Randomized phase 2 trial of the oncolytic virus Pelareorep (Reolysin) in upfront treatment of metastatic pancreatic adenocarcinoma. Mol Ther (2016) 24:1150-8. doi:10.1038/mt.2016.66

125. Freytag SO, Stricker H, Lu M, Elshaikh M, Aref I, Pradhan D, et al. Prospective randomized phase 2 trial of intensity modulated radiation therapy with or without oncolytic adenovirus-mediated cytotoxic gene therapy in intermediate-risk prostate cancer. Int J Radiat Oncol Biol Phys (2014) 89: 268-76. doi:10.1016/j.ijrobp.2014.02.034

126. Xia ZJ, Chang JH, Zhang L, Jiang WQ, Guan ZZ, Liu JW, et al. [Phase III randomized clinical trial of intratumoral injection of E1B gene-deleted adenovirus (H101) combined with cisplatin-based chemotherapy in treating squamous cell cancer of head and neck or esophagus]. Ai Zheng (2004) 23:1666-70.

127. Andtbacka RH, Kaufman HL, Collichio F, Amatruda T, Senzer N, Chesney J, et al. Talimogene laherparepvec improves durable response rate in patients with advanced melanoma. J Clin Oncol (2015) 33:2780-8. doi:10.1200/JCO.2014.58.3377

128. Canavese M, Wijesundara D, Maddern GJ, Grubor-Bauk B, Hauben E. Hepatitis $C$ virus drives the pathogenesis of hepatocellular carcinoma: from immune evasion to carcinogenesis. Clin Transl Immunology (2016) 5:e101. doi: $10.1038 /$ cti.2016.55

129. McCart JA, Ward JM, Lee J, Hu Y, Alexander HR, Libutti SK, et al. Systemic cancer therapy with a tumor-selective vaccinia virus mutant lacking thymidine kinase and vaccinia growth factor genes. Cancer Res (2001) 61:8751-7.

130. Zeh HJ, Downs-Canner S, McCart JA, Guo ZS, Rao UN, Ramalingam L, et al. First-in-man study of western reserve strain oncolytic vaccinia virus: safety, systemic spread, and antitumor activity. Mol Ther (2015) 23:202-14. doi:10.1038/mt.2014.194

131. Downs-Canner S, Guo ZS, Ravindranathan R, Breitbach CJ, O'Malley ME, Jones HL, et al. Phase 1 study of intravenous oncolytic poxvirus (vvDD) in patients with advanced solid cancers. Mol Ther (2016) 24:1492-501. doi:10.1038/mt.2016.101

132. Lawrence MS, Stojanov P, Polak P, Kryukov GV, Cibulskis K, Sivachenko A, et al. Mutational heterogeneity in cancer and the search for new cancerassociated genes. Nature (2013) 499:214-8. doi:10.1038/nature12213

133. Zhang Q, Yu YA, Wang E, Chen N, Danner RL, Munson PJ, et al. Eradication of solid human breast tumors in nude mice with an intravenously injected light-emitting oncolytic vaccinia virus. Cancer Res (2007) 67:10038-46. doi:10.1158/0008-5472.CAN-07-0146

134. Puzanov I, Milhem MM, Minor D, Hamid O, Li A, Chen L, et al. Talimogene laherparepvec in combination with ipilimumab in previously untreated, unresectable stage IIIB-IV melanoma. J Clin Oncol (2016) 34:2619-26. doi:10.1200/JCO.2016.67.1529

135. Long GV, Dummer R, Ribas A, Puzanov I, Michielin O, VanderWalde A, et al. A Phase I/III, multicenter, open-label trial of talimogene laherparepvec (T-VEC) in combination with pembrolizumab for the treatment of unresected, stage IIIb-IV melanoma (MASTERKEY-265). J Immunother Cancer (2015) 3(Suppl 2):P181. doi:10.1186/2051-1426-3-S2-P181

136. Zou W. Immunosuppressive networks in the tumour environment and their therapeutic relevance. Nat Rev Cancer (2005) 5:263-74. doi:10.1038/ nrc1586

137. Sharma P, Hu-Lieskovan S, Wargo JA, Ribas A. Primary, adaptive, and acquired resistance to cancer immunotherapy. Cell (2017) 168:707-23. doi:10.1016/j.cell.2017.01.017

138. Liikanen I, Koski A, Merisalo-Soikkeli M, Hemminki O, Oksanen M, Kairemo K, et al. Serum HMGB1 is a predictive and prognostic biomarker for oncolytic immunotherapy. Oncoimmunology (2015) 4:e989771. doi:10.4161/ 2162402X.2014.989771

139. Mok W, Boucher Y, Jain RK. Matrix metalloproteinases-1 and -8 improve the distribution and efficacy of an oncolytic virus. Cancer Res (2007) 67:10664-8. doi:10.1158/0008-5472.CAN-07-3107

140. Guedan S, Rojas JJ, Gros A, Mercade E, Cascallo M, Alemany R. Hyaluronidase expression by an oncolytic adenovirus enhances its intratumoral spread and suppresses tumor growth. Mol Ther (2010) 18:1275-83. doi:10.1038/ mt.2010.79

141. Diop-Frimpong B, Chauhan VP, Krane S, Boucher Y, Jain RK. Losartan inhibits collagen I synthesis and improves the distribution and efficacy of nanotherapeutics in tumors. Proc Natl Acad Sci U S A (2011) 108:2909-14. doi:10.1073/pnas.1018892108

142. Heldin CH, Rubin K, Pietras K, Ostman A. High interstitial fluid pressure an obstacle in cancer therapy. Nat Rev Cancer (2004) 4:806-13. doi:10.1038/ nrc1456

143. Miller A, Nace R, Ayala-Breton CC, Steele M, Bailey K, Peng KW, et al. Perfusion pressure is a critical determinant of the intratumoral extravasation of oncolytic viruses. Mol Ther (2016) 24:306-17. doi:10.1038/mt.2015.219

144. Thaci B, Ulasov IV, Ahmed AU, Ferguson SD, Han Y, Lesniak MS. Antiangiogenic therapy increases intratumoral adenovirus distribution by inducing collagen degradation. Gene Ther (2013) 20:318-27. doi:10.1038/ gt. 2012.42

145. Spitzer MH, Carmi Y, Reticker-Flynn NE, Kwek SS, Madhireddy D, Martins $\mathrm{MM}$, et al. Systemic immunity is required for effective cancer immunotherapy. Cell (2017) 168:487-502.e415. doi:10.1016/j.cell.2016.12.022

146. Meisen WH, Wohleb ES, Jaime-Ramirez AC, Bolyard C, Yoo JY, Russell L, et al. The impact of macrophage- and microglia-secreted TNFalpha on oncolytic 
HSV-1 therapy in the glioblastoma tumor microenvironment. Clin Cancer Res (2015) 21:3274-85. doi:10.1158/1078-0432.CCR-14-3118

147. Han J, Chen X, Chu J, Xu B, Meisen WH, Chen L, et al. TGFbeta treatment enhances glioblastoma virotherapy by inhibiting the innate immune response. Cancer Res (2015) 75:5273-82. doi:10.1158/0008-5472.CAN-150894

148. Galivo F, Diaz RM, Wongthida P, Thompson J, Kottke T, Barber G, et al. Single-cycle viral gene expression, rather than progressive replication and oncolysis, is required for VSV therapy of B16 melanoma. Gene Ther (2010) 17:158-70. doi:10.1038/gt.2009.161

149. Li X, Wang P, Li H, Du X, Liu M, Huang Q, et al. The efficacy of oncolytic adenovirus is mediated by T-cell responses against virus and tumor in Syrian hamster model. Clin Cancer Res (2017) 23:239-49. doi:10.1158/1078-0432. CCR-16-0477

150. Prestwich RJ, Errington F, Diaz RM, Pandha HS, Harrington KJ, Melcher AA, et al. The case of oncolytic viruses versus the immune system: waiting on the judgment of Solomon. Hum Gene Ther (2009) 20:1119-32. doi:10.1089/hum.2009.135

151. Roy S, Trinchieri G. Microbiota: a key orchestrator of cancer therapy. Nat Rev Cancer (2017) 17:271-85. doi:10.1038/nrc.2017.13

Conflict of Interest Statement: The authors declare that the research was conducted in the absence of any commercial or financial relationships that could be construed as a potential conflict of interest.

Copyright (C) 2017 Guo, Liu, Kowalsky, Feist, Kalinski, Lu, Storkus and Bartlett. This is an open-access article distributed under the terms of the Creative Commons Attribution License (CC BY). The use, distribution or reproduction in other forums is permitted, provided the original author(s) or licensor are credited and that the original publication in this journal is cited, in accordance with accepted academic practice. No use, distribution or reproduction is permitted which does not comply with these terms. 